\title{
Antracología y paleoecología en el cuadrante suroriental de la Península Ibérica: las aportaciones del yacimiento de la Edad del Bronce de Terlinques (Villena, Alicante)
}

\author{
Anthracology and paleoecology in the south-eastern quadrant of the Iberian Peninsula: \\ the contributions of the Bronze Age settlement of Terlinques (Villena, Alicante province)
}

\author{
María del Carmen Machado Yanes (*) \\ Francisco Javier Jover Maestre (**) \\ Juan Antonio López Padilla (***)
}

Palabras clave: Antracología; Paleoecología; Edad del Bronce.

Key words: Anthracology; Palaeoecology; Bronze Age.

\section{INTRODUCCIÓN}

La biomasa vegetal existente en cualquier territorio, y más en concreto los bosques, ha constituido un importante conjunto de recursos naturales necesarios para el mantenimiento y reproducción de los grupos humanos. El afianzamiento de las prácticas agrícolas y ganaderas significaron, sin duda, un aumento de la presión antrópica sobre los territorios circundantes a los lugares de asentamiento, generando cambios en la cobertura vegetal y modelando un paisaje humanizado, donde la oferta y cantidad de los recursos vegetales existentes se fueron sustituyendo a medida que los grupos humanos fueron aumentando.

Es difícil determinar si los cambios en el paisaje y en la biomasa vegetal pueden ser observados en los contextos arqueológicos, ya que solamente una parte del registro vegetal se conserva (Piqué 2006). Los restos de madera carbonizada dispersos en los sedimentos y los que proceden de estructuras de combustión como pueden ser los hogares, son los que permiten, a través de los estudios antracológicos, aproximarnos a las características ecológicas del pasado. De hecho, en algunos yacimientos arqueológicos, los menos, la destrucción de edificios o viviendas como resultado de un
(*) 57 rue Basse. 30114 Nages et Solorgues. Francia. Correo electrónico: carmaya@neuf.fr

(**) Área de Prehistoria. Universidad de Alicante. Apto. 99 Alicante. Correo electrónico: javier.jover@ua.es

(***) Museo Arqueológico Provincial de Alicante. MARQ Pl. Gómez Ulloa s/n. 03013. Alicante.

Correo electrónico: japadi@dip-alicante.es

Recibido: 8-IX-2008; aceptado: 9-II-2009. 
incendio y su posterior abandono sin grandes alteraciones han permitido la conservación de numerosos restos vegetales carbonizados, empleados no sólo como combustible en hogares, sino también como instrumentos y, especialmente, como elementos del entramado constructivo -techo, paredes, postes de sustentación-, donde los troncos y ramajes seleccionados constituyeron los materiales básicos junto a la tierra para su edificación (Grau 1998). Es en estos casos donde la calidad de la información disponible en relación con el registro botánico resulta más cercana a la realidad en estudio, razón por la que consideramos prioritarios los análisis de este tipo de contextos.

En este sentido, el interés del presente estudio antracológico realizado en el poblado de la Edad del Bronce de Terlinques (Villena, Alicante) reside en las excepcionales condiciones de conservación del yacimiento como consecuencia de diferentes incendios súbitos, materializados en el registro arqueológico con pocas transformaciones posdeposicionales (Schiffer 1977). A ello debemos sumar la aplicación de una metodología sistemática de recogida de carbones en la que se han combinado diversos procedimientos que han permitido interpretar y diferenciar los restos procedentes de hogares y los artefactos o instrumentos de trabajo, de los niveles de derrumbe de los edificios incendiados, a lo largo de una secuencia próxima a los 600 años de ocupación del asentamiento -entre c. 2100-1500 AC-.

Con todo, el análisis del amplio registro antracológico de Terlinques hace posible una lectura de carácter paleoecológica, que unida a los diferentes estudios antracológicos y palinológicos realizados en el cuadrante suroriental de la Península Ibérica permite contribuir al debate sobre el proceso de desertificación en la zona.

\section{ALGUNAS CONSIDERACIONES METODOLÓGICAS}

Antes de abordar los estudios realizados en Terlinques, consideramos necesario exponer una serie de precisiones metodológicas. En primer lugar, no podemos obviar que la presencia y uso de diferentes tipos de maderas -carbonizadas o noen los yacimientos arqueológicos normalmente será el resultado de actividades humanas y no de procesos naturales. La presencia de determinados taxones en un contexto arqueológico responderá a una intencionalidad antrópica como es la de cubrir las propias necesidades, teniendo presente la oferta vegetal que ofrece el medio, el conocimiento que se poseía de las características de cada una de las especies y los posibles usos a los que pudieron destinarse.

Podríamos decir que el factor que condiciona cómo las comunidades humanas efectúan el aprovisionamiento del combustible es la disponibilidad medioambiental, mientras que las pautas culturales son la que establecen cómo se efectúa la recolección, siendo su objetivo principal la determinación de los patrones de uso (Piqué 1999). No obstante, existen limitaciones como la dificultad de reconocer las comunidades vegetales en los conjuntos antracológicos, la de inferir la cantidad de biomasa a partir de los residuos, o la imposibilidad, en algunos casos, de determinar los restos a nivel de especies.

A pesar de las limitaciones señaladas, consideramos que se puede realizar una lectura paleoecológica, aunque sea simplemente una tentativa de representación de lo que pudo ser la realidad, siempre y cuando se pueda aplicar una metodología de registro que permita la interpretación de los restos, teniendo presente todos los procesos de formación del contexto arqueológico del que proceden (Schiffer 1976; 1977). En este sentido, las excepcionales condiciones de conservación del registro arqueológico en Terlinques han permitido determinar, en buena medida, los procesos de formación del depósito. Por este motivo, se ha seguido una estrategia de registro en la que se han concatenado tres procedimientos de recogida. Por un lado, una parte importante de los carbones, aquellos que estaban mejor conservados y que permitían su orientación y asociación con otros elementos, fueron coordenados tridimensionalmente e individualizados como unidad. Es importante resaltar que en el proceso de excavación se pudo observar cómo un buen número de carbones que, en principio, podrían considerarse como elementos aislados, realmente correspondían a partes separadas pero integrantes de troncos carbonizados caídos sobre los pavimentos de las unidades habitacionales, por lo que metodológicamente fue necesario considerarlos de forma agrupada, otorgándoles un único número de registro. No haber reconocido este extremo hubiera significado cometer un error estadístico grave que alteraría la representatividad de las diferentes especies documentadas y la interpretación paleoecológica. 
Por otro, se realizó una recogida manual individualizada de carbones de pequeño tamaño, difícilmente orientables y relacionables con los registrados por el procedimiento anterior. Por último, a todo ello se ha de unir el tamizado en seco con malla de $3 \mathrm{~mm}$ en todas y cada una de las unidades estratigráficas. La concatenación de estos tres procedimientos ha permitido evitar, en la medida de lo posible, algunos de los errores ligados a la fragilidad de la muestra.

Posteriormente, ya en el laboratorio, el análisis ha consistido en la observación de cada fragmento de carbón en un microscopio óptico de reflexión de fondo oscuro, con una capacidad de 100 a 800 aumentos. Para ello es necesario romper el carbón en busca de los tres planos anatómicos que caracterizan las especies (transversal, longitudinal-tangencial y longitudinal-radial), a fin de observar los caracteres anatómicos que son claves para su identificación. En esta fase del análisis, la colección de referencia de madera actual y los atlas de anatomía de madera son los útiles esenciales para identificar las especies (Schweingruber 1990).

En cuanto al tamaño de los fragmentos, el diámetro de los carbones oscila entre $0,5 \mathrm{~cm}$ y algo más de $14 \mathrm{~cm}$ para algunos de los troncos localizados sobre los pavimentos, interpretados como postes y como parte del entramado de la techumbre. Los que presentan una talla igual o superior a $5 \mathrm{~mm}$ fueron recogidos y analizados en su totalidad, así como algunos de talla inferior, pues según los estudios realizados para el período protohistórico (Chabal 1988) las inferencias que podemos realizar sobre la flora no están en función del tamaño de los carbones. El material antracológico que hemos analizado puede ser calificado como material carbonizado cuyo uso fue de corta y amplia duración, ya que se ha podido diferenciar claramente las maderas carbonizadas empleadas como postes, vigas, largueros y travesaños en las edificaciones, de aquellos que fueron empleados como combustible en hogares o como instrumentos en uso y/o almacenados.

\section{TERLINQUES Y SU MARCO BIOGEOGRÁFICO: EL VALLE DEL VINALOPÓ}

El área donde se ubica el yacimiento de Terlinques es una zona de transición entre la tectónica Ibérica y la Bética, en la que destacan impor-

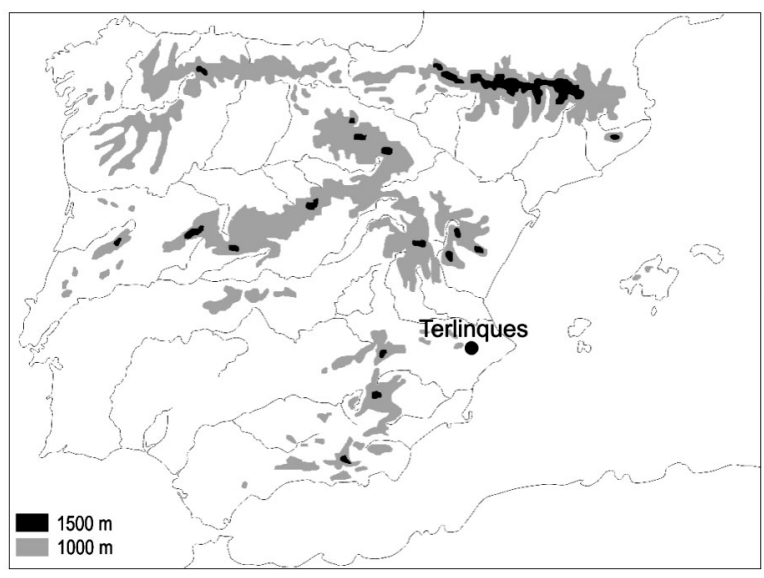

Fig. 1. Ubicación de Terlinques en el contexto peninsular.

tantes alineaciones montañosas con dirección SO-NE - constituyendo la sierra de Salinas la máxima elevación con 1.112 m s.n.m.- sobre amplios corredores situados en torno a la cota de los 520 m s.n.m. Entre ellos destaca especialmente, el corredor central longitudinal, conocido como valle o corredor del Vinalopó, el cual imprime un carácter paisajístico muy peculiar, "como una puerta desde el litoral a la meseta donde convergen las más variadas influencias, tanto desde un punto de vista físico, como biogeográfico como humano" (Alonso 1996: 9).

El valle de Villena se localiza al sureste de la Península Ibérica, en la parte más occidental de la provincia de Alicante. Ocupa un espacio de 94 $\mathrm{km}^{2}$, que comprende parte de los municipios de Villena y Sax. Es un territorio límite o frontera entre la Meseta (corredor de Almansa), Murcia y el litoral levantino, aspecto que incide en las condiciones climáticas. Aquí, la influencia marítima es menor que en las comarcas valencianas vecinas, pero en cambio se dejan sentir ciertas influencias de la Meseta como la frecuencia de las nieblas de irradiación y las heladas invernales.

En este territorio, la red fluvial queda reducida a pequeños arroyos de escorrentía, ramblas y zonas endorreicas entre las que se encontraba la Laguna de Villena (1), la Lagunilla o El Balsón. Justamente al sur de la Laguna de Villena se ubica el

(1) La primera fase en la desecación de la Laguna de Villena tuvo lugar en 1803, basada en un proyecto de 1785 que tenía por finalidad erradicar las fiebres, y que culminó en 1806. La desecación de esta zona pantanosa supuso un cambio económico y paisajístico. Actualmente, el paulatino abandono de los cultivos ha producido una mayor salinización del suelo (Matarredona 1983).

T. P., 66, N. ${ }^{\circ} 1$, enero-junio 2009 , pp. $75-97$, ISSN: 0082-5638 doi: $10.3989 /$ tp.2009.09013 


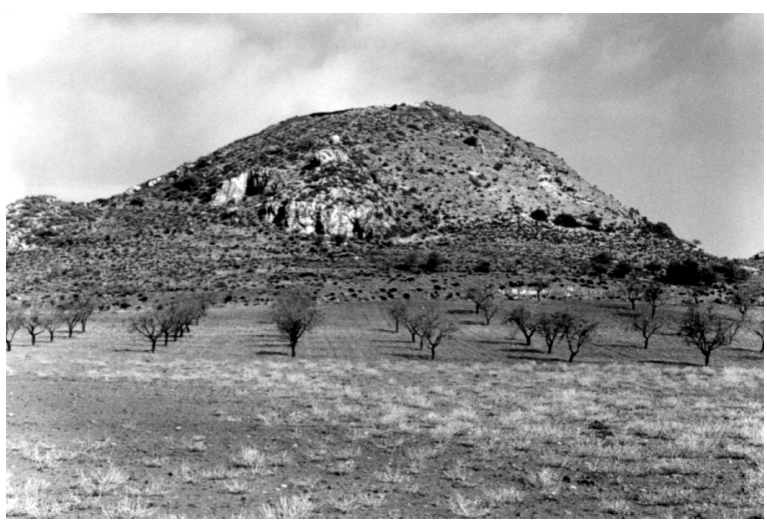

Lám. I. Foto de Terlinques. Ladera meridional.

cerro de Terlinques, a $4 \mathrm{~km}$ al suroeste de la localidad de Villena. Sus coordenadas UTM son 30SXH8028749. Este cerro de origen triásico (yesos y arcillas) presenta una cresta de dolomías calizas que lo recorre longitudinalmente, extendiéndose el asentamiento aproximadamente sobre algo más de $1.300 \mathrm{~m}^{2}$. La visibilidad potencial del yacimiento es alta, ya que desde el mismo se observa toda la banda central del corredor del Vinalopó y la antigua Laguna del Rey o de Villena.

La comarca del Alto Vinalopó, según la clasificación establecida por E. Matarredona (1983), se sitúa en un grado -montano-submediterráneocaracterizado por la presencia mayoritaria de la encina o carrasca (Quercus ilex), que desde hace décadas ha sido suplantada por el pino carrasco (Pinus halepensis) y en menor medida, por el fresno (Fraxinus ornus) y el serbal silvestre (Sorbus aria) y por un matorral formado por la coscoja, la aliaga y el lentisco. Esta zona quedaría incluida dentro del ámbito climático mesomediterráneo de carácter continental, con una temperatura media anual entre $13^{\circ}$ y $17^{\circ} \mathrm{C}$, y una amplitud térmica elevada (de hasta $15^{\circ} \mathrm{C}$ ), con inviernos frescos, heladas en los meses más fríos $\mathrm{y}$ veranos calurosos. El régimen pluviométrico actual nos informa de un ombroclima semiárido, con precipitaciones de 200-350 mm (Forteza et al. 1995). Valores similares a los que presenta Alonso para la estación de Villena (2).

(2) Aunque hay que tener en cuenta, como precisa Alonso (1996), que la estación de Villena no se localiza en el valle y los datos son insuficientes porque se refieren a 22 años, no a 30 que son los mínimos necesarios para que los datos sean fiables. De otra parte, no se puede desestimar otro aspecto, la oscilación térmica que es muy acusada, en invierno los días sin viento las nieblas persisten y reflejan casi toda la radiación solar provocando
Por otro lado, el termotipo es mesomediterráneo superior, principalmente en las partes bajas del valle, porque en la mayor parte de los relieves, sobre todo, en las exposiciones a mediodía, el horizonte que aparece es mesomediterráneo inferior. Es éste uno de los hechos más interesantes desde un punto de vista bioclimático y biogeográfico. La rigurosidad climática facilita la aparición de elementos vegetales propios de áreas interiores y, por otra parte, la cercanía a los territorios murcianos-almerienses, favorecen el desarrollo de plantas de óptimo más litoral.

El ombrotipo (valor medio anual y distribución estacional) en el valle y en los relieves más meridionales es semiárido, mientras que para el resto de las elevaciones es seco. Villena con precipitaciones medias de $373 \mathrm{~mm}$ entra dentro del grupo seco. La distribución estacional de las precipitaciones en Villena refleja un máximo primaveral acusado, que puede llegar a superar el porcentaje de lluvias de otoño. Esta aproximación en los valores primaverales y de otoño es una prueba más del carácter fronterizo del valle y repercute en la distribución de los taxones y de las comunidades vegetales (Alonso 1996: 229).

Resumiendo, las características climáticas son alto índice de continentalidad y ombrotipo semiárido-seco, incluyéndose la zona, biogeográficamente, en el subsector Aroyano-Villenense que limita con dos provincias corológicas: la Murciano-Almeriense y la Castellano-Maestrazgo-Manchega.

La serie climática que domina en el paisaje es el carrascal Quercetum rotundifoliae arenarietosum intrincati. En las zonas de mayor insolación aparece el lentiscar murciano-almeriense $\mathrm{Cha}$ maeropo-Rhamnetum lycioidis. Y en las zonas de

\footnotetext{
temperaturas muy bajas. En verano ocurre lo contrario, las temperaturas son muy altas porque los relieves que rodean el valle provocan recalentamientos. Por las razones expuestas antes sobre los datos de las estaciones se pueden suponer que las temperaturas en invierno dentro del valle serán más bajas que lo que reflejan las tablas y en verano lo contrario. Las temperaturas para la estación de Villena, con una altitud 505 m s.n.m., son las siguientes:
}

$\begin{array}{ll}\text { Temperatura media enero: } 5,9^{\circ} \mathrm{C} & \text { Temperatura media agosto: } 22,6^{\circ} \mathrm{C} \\ \text { T. máxima enero: } 12,1^{\circ} \mathrm{C} & \text { T. máxima agosto: } 31^{\circ} \mathrm{C} \\ \text { T. mínima enero: }-0,4^{\circ} \mathrm{C} & \text { T. mínima agosto: } 14,1^{\circ} \mathrm{C}\end{array}$

Precipitaciones: la media anual es $373 \mathrm{~mm}$ (enero: 24,7; mayo: 41,5 ; agosto: 18,8 y octubre: 55,8 ). Índice de continentalidad: 16,2 (IC $=$ T máx.-T min. se encuentra entre el intervalo 8-18), It. 262 Itc: 262. 
mayor degradación se extienden los matorrales que, dependiendo del ombrotipo y de la continentalidad, están integrados por distintos elementos florísticos. Entre los matorrales aparecen los pastizales vivaces y los espartales (Alonso 1996: 235).

En el catálogo realizado sobre la vegetación actual del valle de Villena se han contabilizado 697 taxones, con claro dominio de plantas terófitas (nitrófilos y no nitrófilos) y otros grupos caméfitos (tomillares). El grupo mediterráneo es el mejor representado. La combinación de los componentes del clima -temperatura, presión, altitud y latitud- junto a los factores geográficos -orografía, geología, litología, etc.- determina el ecosistema vegetal de la región, asociando el piso a la maquia continental, formada por diferentes matorrales y arbustos. Por otro lado, debemos tener presente que en las zonas bajas con suelos pedregosos se desarrollan plantas como el tomillo (Thymus viscosum) o el rabo de gato (Aporocactus flagilliformis), entre otros, mientras que la vegetación de las seudoestepas se traduce en la presencia del esparto (Lygeum spartium).

En cuanto a las formaciones edafófilas, ligadas a las áreas lacustres, encharcadas y cursos de agua, señalamos que en torno a las primeras, se concentran, por su contenido en sales, diversas gramíneas, romero y otros matorrales y arbustos aislados. Sin embargo, en el caso de los ríos, la vegetación está constituida por olmos (Ulmus sp.), sauces (Salix sp.), chopos (Populus sp.) y adelfas (Nerium oleander).

No obstante, a la hora de hablar de la vegetación y del paisaje actual debemos tener presente que han experimentado un fuerte proceso de alteración en los últimos siglos, en especial desde la desecación de la Laguna del Rey o de Villena a inicios del siglo XIX. El primer cambio a resaltar es la considerable ampliación de la superficie cultivada. En las cercanías del yacimiento abundan el esparto, las plantas aromáticas y un pinar de repoblación plantado en el año 1971, y en los campos de cultivo más próximos la vid, almendros, olivos y árboles frutales.

La roca madre, el clima y la vegetación han contribuido a la formación de los suelos, cuya composición litológica es determinante. De este modo, tenemos suelos aluvio-coluviales y pardocalizos en el fondo de la cubeta de Villena, con una capacidad de uso elevada -clase A y B en la clasificación de E. Matarredona (1983)-. Mien- tras que para los suelos de composición calcárea de las áreas montañosas, la capacidad es muy reducida. La acción antrópica ha aumentado la erosión de estos suelos y ha alterado la vegetación que se ha visto muy afectada por la deforestación antigua, la desecación de las áreas lacustres y la reciente reforestación.

\section{LA HISTORIA DE TERLINQUES: LAS FASES DE OCUPACIÓN}

Aunque en el año 1969 se realizó una primera campaña de excavaciones (Soler y Fernández 1970), la actuación sistemática se inició en el año 1997 y se mantienen de forma ininterrumpida hasta la actualidad (3). Las subvenciones económicas con las que se cuenta anualmente permiten realizar una campaña de aproximadamente un mes, habiendo actuado hasta el momento en una superficie superior a los $500 \mathrm{~m}^{2}$.

En la zona excavada, correspondiente a la cima y ladera oriental del extremo occidental del cerro, se ha podido documentar una larga ocupación, constatándose la superposición de diversos edificios interpretados como viviendas. Los procesos erosivos de ladera y diversos procesos naturales, biológicos y antrópicos han afectado considerablemente a la conservación del yacimiento, pudiendo señalar que mientras en los momentos iniciales -fases I y II- se mantienen en buenas condiciones las zonas más meridionales y bajas de ocupación del edificio, de la fase final -fase III- se conservan, en mayor medida, las zonas más elevadas de la cima. En cualquier caso, esta tercera fase supuso una gran transformación de la gestión del espacio, al planificar nuevamente la distribución de las viviendas.

Por ello, mientras de la fase I y II se conservan en buenas condiciones los conjuntos estratigráficos correspondientes a dos viviendas de grandes dimensiones, que fueron asoladas por sucesivos incendios, en la fase III el poblado sufrió una radical transformación, estructurándose la ocupación en pequeñas unidades habitacionales adosadas y ubicadas a lo largo de una calle o pasillo

(3) Terlinques es un proyecto de investigación de la Universidad de Alicante dirigido por Francisco Javier Jover Maestre y Juan A. López Padilla, autorizado y subvencionado por la Direccion General de Patrimonio de la Conselleria de Cultura y Educación de la Generalitat Valenciana. 


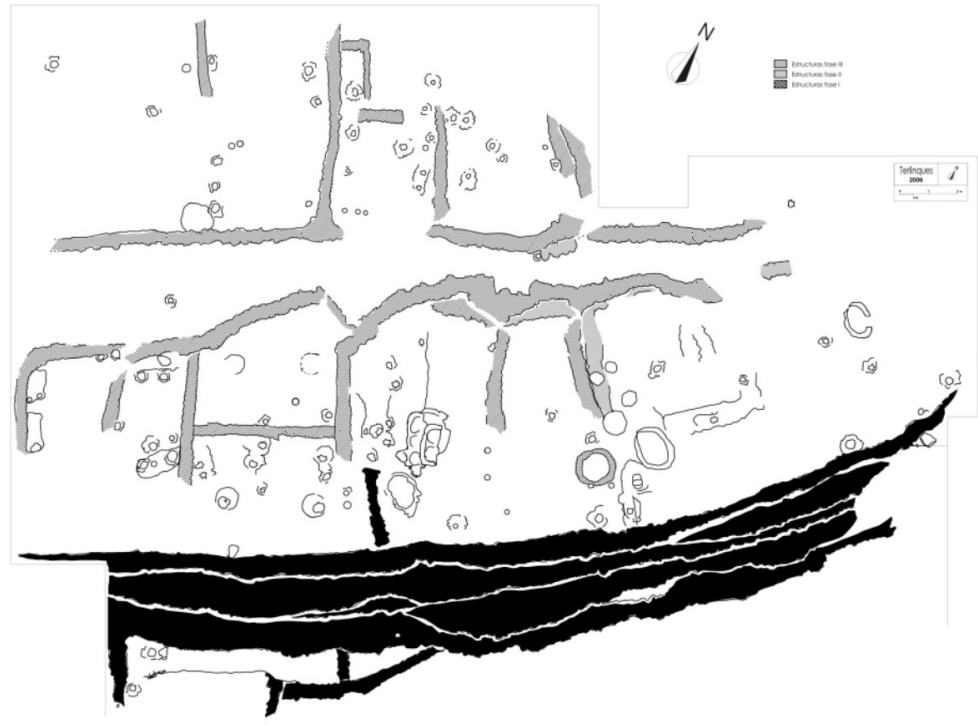

Fig. 2. Plano del área excavada en Terlinques con diferenciación de fases constructivas.

central. Estas pequeñas viviendas es probable que estuviesen integradas por dos ambientes, cubriendo los conjuntos sedimentarios de las fases I y II en las zonas más meridionales, aunque por el momento este extremo no puede ser contrastado ya que la erosión ha destruido buena parte de estas zonas. No obstante, estas circunstancias no han impedido que la calidad de la información recuperada sea elevada.

En cuanto a la cronología del asentamiento podemos decir que en este momento contamos con 15 dataciones absolutas, tanto de muestras de vida larga, como especialmente de vida corta de las diferentes fases. La fase I se iniciaría sobre el c. 2100 AC, finalizando hacia el 1900 AC como consecuencia de un incendio. La fase II, mantendría básicamente la misma estructura urbanística hasta aproximadamente el $1700 \mathrm{AC}$, coincidiendo también con otro incendio. Por último, la fase III, iniciada sobre el $1700 \mathrm{AC}$, supuso una enorme transformación del asentamiento prolongándose hasta su abandono definitivo sobre el 1500 AC (Jover y López 2004).

Desde el punto de vista constructivo, destaca la gran unidad habitacional $n .^{\circ} 1$ de la fase I. Se trata de una habitación de planta con tendencia rectangular adaptada a las irregularidades del terreno, construida con muros de doble cara de piedra local, empleando como material unitivo arcillas triásicas y posiblemente yesos no elabo- rados, además de limos para el enlucido. La cubierta, construida con madera, paja, ramas de distintos arbustos y yeso con limos, es probable que tuviera sólo una vertiente y que estuviera sustentada mediante un sistema de vigas apoyadas sobre postes de madera calzados con mampostería.

El tamaño de los calzos de poste varía en relación con su emplazamiento. Los de mayor tamaño, con un diámetro en torno a $40 \mathrm{~cm}$, se localizan precisamente adosados al muro meridional inferior-Ue 2006-, dado que tuvieron que soportar todo el peso de la estructura, mientras que los

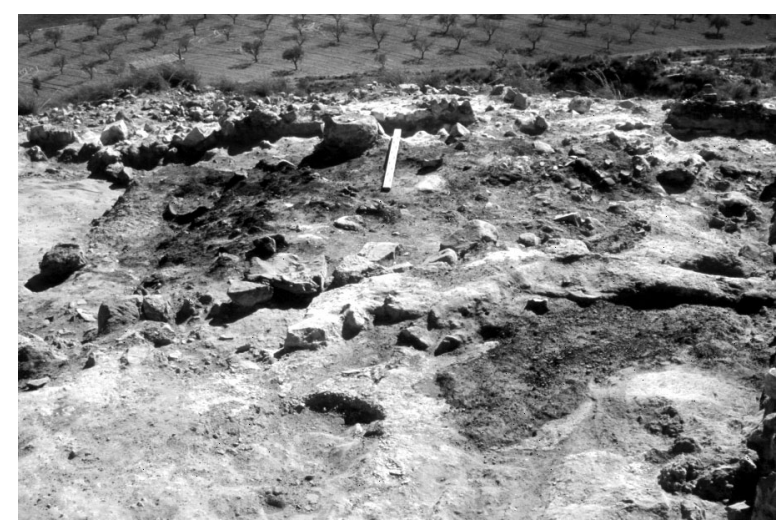

Lám. II. Foto de la Ue 1009 de la fase I de Terlinques en proceso de excavación. 
que los situados en la zona central de la habitación alcanzan los 20/25 cm.

El suelo de la habitación (Ue 1012), al igual que las del resto, estaban pavimentadas con un sedimento fino con alto contenido en yeso y nivelado en algunas zonas con un relleno de cantos calizos y tierra. En el interior de la habitación se ha podido observar la existencia de espacios delimitados: un área de almacenamiento de diversos productos, en la que se ha reconocido una cubeta próxima a un metro de diámetro y de planta ovalada (Ue 2023) y sección en "U" que pudo destinarse a contener líquidos y una especie de banco o realce en el suelo de unos $20 \mathrm{~cm}$. Este banco o repisa creó una zona ligeramente rehundida al norte del mismo, que se utilizó para extender los cereales. Precisamente en el rehundimiento que generaba el banco, se localizaron luchaderas de ciervo y un grupo de pequeños palos de madera aguzados. En la zona meridional del realce se acondicionó el espacio a modo de estantería o poyo para colocar vasijas.

El segundo elemento separador es un tabique interno con disposición $\mathrm{N}-\mathrm{S}$ de un metro y medio de longitud realizado con una alineación de ocho troncos manteados, que tienen un diámetro comprendido entre 8 y $14 \mathrm{~cm}$. En esta zona se encontraban cuatro sacos de esparto; tres contenían cereales y uno estiércol. Su disposición nos permite suponer que se encontraban colgados o situados en altura, en una especie de repisa o estante de madera apoyada en el muro meridional.

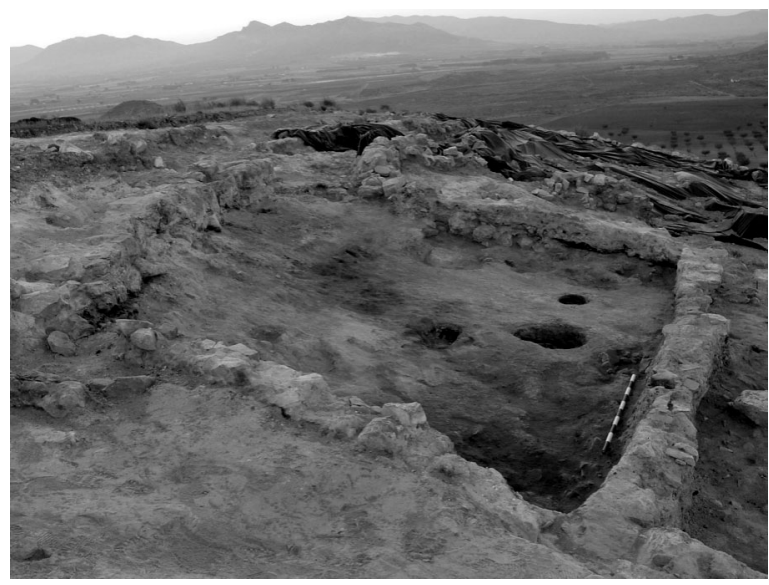

Lám. III. Unidad habitacional 7 de la fase III de Terlinques.
En cuanto a la estratigrafía, en la unidad habitacional $n .^{\circ} 1$ se reconocen varias unidades estratigráficas y diversas estructuras cuya funcionalidad se relaciona con áreas de transformación de cereales y almacenamiento. De ellas nos interesan, sobre todo, las Ues 1006, 1009 y 1012. La Ue 1006 es heterogénea en su composición como consecuencia del derrumbe de la techumbre y paredes durante y con posterioridad al incendio. En esta capa aparecieron materiales que integraban las paredes, la techumbre y algunos enseres domésticos. La Ue 1009, cubierta por 1006, corresponde a una capa de tono negruzco de entre 2 y $12 \mathrm{~cm}$ de espesor, integrada por un sedimento muy fino con alto contenido en materia orgánica -carbones y fibras vegetales desechas- que interpretamos como la materialización de un nivel de incendio que produjo el abandono del edificio. Aunque esta unidad la encontramos en casi toda la superficie cubriendo al pavimento Ue 1012, existen algunos puntos donde el derrumbe de paredes y techumbre (Ue 1006) se localiza de forma directa sobre el mismo. En esta capa se registraron la mayor parte de los enseres domésticos, así como los carbones de mayor tamaño que corresponden a los postes de tabiques internos y largueros de techumbre. De este primer momento también es interesante destacar la presencia de una estructura ovalada de más de un metro de tamaño con un ligero rehundimiento en su interior (Ue 2041), que estaba rellenado por una gran cantidad de materia orgánica carbonizada (Ue 1041). Esta estructura es interpretada como un hogar. Después del incendio, se produjo una reocupación de la zona, reutilizando parte del edificio anterior, aunque la escasa superficie documentada y los procesos antrópicos desarrollados durante la III fase, hacen de este momento el peor conocido del asentamiento.

Por último, cabe señalar la importante reestructuración que sufrió el poblado a partir del 1700 AC, aproximadamente -inicio de la fase III-, momento en el que sobre el derrumbe de la fase II se reestructuró todo el espacio, creando conjuntos de viviendas adosados de planta rectangular o trapezoidal, cuyo vano se orientaba a un pasillo central o calle. Mientras el acceso de las viviendas meridionales daba a este pasillo, las casas de la manzana septentrional situadas en la cima también tenían sus zonas de acceso orientados al norte. A pesar de que los procesos erosivos son mucho más elevados en los momentos finales 
de la ocupación, en algunas unidades habitacionales se ha podido documentar hasta dos pavimentaciones, algunas de las cuales también fueron asoladas por un incendio, especialmente las unidades habitacionales 7, 9, 10, 11 y 12 .

\section{RESULTADOS DEL ANÁLISIS ANTRACOLÓGICO}

El análisis antracológico nos aporta datos sobre la vegetación leñosa existente en el entorno del yacimiento y sobre los mecanismos de selección del combustible. En ese sentido, los restos de madera carbonizados son un recurso económico que se tiene que analizar en relación con parámetros como la gestión del territorio y el desarrollo técnico y social del grupo humano. La dualidad de esta disciplina nos permite realizar una doble lectura del registro antracológico. En este trabajo los datos del antracoanálisis, por su interés y complejidad, serán tratados únicamente desde la perspectiva paleoecológica, ya que el enfoque etnobotánico ya ha sido objeto de otro artículo (Machado et al. 2004).

Se han estudiado un total de 3.720 fragmentos de carbón, que fueron recogidos en las campañas de excavación efectuadas entre 1997 y 2005. Se trata de muestras de diferentes tamaños que proceden de un total de 33 unidades estratigráficas de las tres fases de ocupación reconocidas en Terlinques -1006, 1009 y 1041 de la fase I, 1048, 1061 y 1066 de la fase II y un amplio número de unidades de la fase III- (Tab. 1, 2 y 3). Para el análisis, de la fase III únicamente incluimos los conjuntos de algunos ambientes (unidades habitacionales 5,6 y 7 y paquete de nivelación de la ca1le), cuyo número de frecuencias es lo suficientemente amplio como para realizar una tentativa de comparación entre fases.

En su mayor parte corresponden a unidades sedimentarias interpretadas como derrumbes de diferentes unidades habitacionales o ambientes, mientras que, en pocos casos, corresponden a hogares -Ue 1041 de la fase I- o desechos reutilizados para nivelar-Ue 1048, fase II y Ue 1106 de la calle, fase III.

El número de fragmentos determinados por fases y unidades estratigráficas seleccionadas es lo suficientemente numeroso como para poder comparar estadísticamente los resultados. Mientras las unidades estratigráficas de la fase I y II proceden de una única unidad habitacional de gran tamaño respectivamente, las estudiadas de la fase III proceden de, al menos, tres unidades habitacionales y un espacio de paso situado entre éstas.

Por otro lado, el número de carbones por unidad estratigráfica también es bastante dispar, aunque las principales unidades superan las 200 muestras analizadas de cada una, no variando sustancialmente, ni los taxones, ni el porcentaje de representación, con las diferencias, claro está, que se establecen entre los conjuntos procedentes de niveles de derrumbe, de los recogidos en hogares o paquetes de nivelación donde la variedad es mayor.

En este sentido, la comparación por fases de diversas unidades estratigráficas en el que el número de carbones analizados se ha estimado como estadísticamente significativo, evidencia una representatividad similar si tenemos en cuenta un factor importante como es el grado de disgregación. La comparación de los conjuntos analizados de las unidades de derrumbe de las distintas fases -Ue 1006/1009 de la habitación 1 de fase I, la Ue 1061/1066 de la habitación 2 de fase II y las Ues 1052 de la UH 5, 1068 de la UH 6 y 1073 de la UH 7 de la fase III (Tab. 1, 2 y 3)-, teniendo en cuenta que el área excavada respectivamente de cada fase es aproximadamente de $77,56,45,6$ y $41,47 \mathrm{~m}^{2}$ y el volumen sedimentario de $19,39,5,47$ y $8,7 \mathrm{~m}^{3}$ respectivamente, permite determinar que el número de muestras analizadas por $\mathrm{m}^{3}$ asciende a 28,31 en la fase I, 63,43 en la fase II y 76,20 en la fase III, diferencias que desde nuestro punto de vista se explican por el diferente grado de disgregación de las muestras que va aumentando a medida que nos acercamos a los niveles más superficiales del yacimiento donde el grado de erosión ha sido mucho mayor. Mientras en la unidad estratigráfica 1009 de la fase I, buena parte de las muestras corresponden a troncos enteros carbonizados cuya longitud superaba los $12 \mathrm{~cm}$, en las unidades de las fases II y III, los carbones no superaban los $4 \mathrm{~cm}$ y se encontraban plenamente disgregados.

Aunque podamos establecer comparaciones entre las distintas unidades estratigráficas seleccionadas, reconocidas o interpretadas como resultado de la destrucción de edificaciones a lo largo la secuencia de ocupación del yacimiento, y de las que en principio, cabe esperar una composi- 


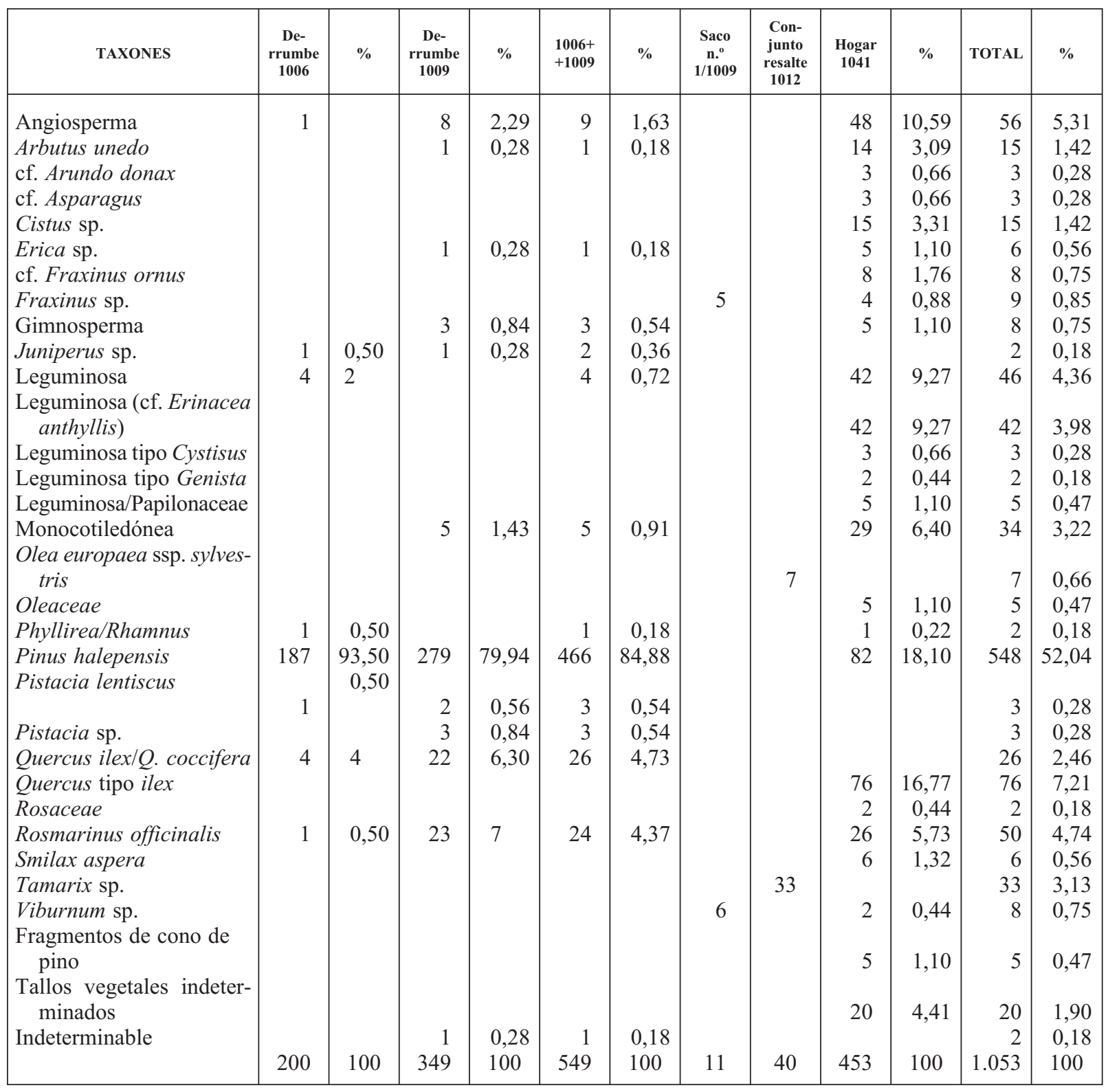

Tab. 1. Taxones identificados en valores absolutos y relativos en las unidades estratigráficas de la fase I de Terlinques. Se diferencia entre los paquetes de derrumbe (Ues 1006 y 1009), conjuntos aislados sobre el pavimento Ue 1012 (saco n. ${ }^{\circ} 1$ y resalte 1012) y el conjunto del hogar 1041. Las categorías taxonómicas se presentan siguiendo el orden alfabético y la nomenclatura propuesta en Flora Europaea.

ción similar en cuanto a su materia constructivo (mampuesto, tapial, ramajes, etc.), debemos tener presentes las limitaciones que implica el establecimiento de valoraciones sobre las mismas y, mucho más, realizar apreciaciones de carácter general sobre el conjunto de los taxones documentados. A pesar de ello, consideramos que es necesario desarrollar este tipo de análisis, siempre y cuando se tomen las debidas precauciones interpretativas.

Así, en conjunto, los resultados del análisis confirman la presencia y abundancia relativa de Pinus halepensis en todas las unidades estratigráficas con un porcentaje medio próximo al $77 \%$. En menor medida aparecen Quercus ilex/Q. coccifera con un porcentaje en torno a $6,48 \%$; le si- 


\begin{tabular}{|c|c|c|c|c|c|c|c|c|}
\hline & $\begin{array}{c}\text { De- } \\
\text { rrumbe } \\
1061\end{array}$ & $\begin{array}{c}\text { De- } \\
\text { rrumbe } \\
1066\end{array}$ & $\begin{array}{c}1061+ \\
+1066\end{array}$ & $\%$ & $\begin{array}{c}\text { Nivela- } \\
\text { ción } \\
1048\end{array}$ & $\%$ & TOTAL & $\%$ \\
\hline $\begin{array}{l}\text { TAXONES } \\
\text { Asparagus sp. } \\
\text { Chenopodium sp. } \\
\text { Cistus sp. } \\
\text { Erica } \text { sp. } \\
\text { cf. Fraxinus ornus } \\
\text { Leguminosa tipo Cystisus } \\
\text { Leguminosa cf. Erinacea anthyllis } \\
\text { Leguminosa/Papilonaceae } \\
\text { Monocotiledónea cf. Pragmitis } \\
\text { Pinus halepensis } \\
\text { Pistacia sp. } \\
\text { Quercus ilex /Q. coccifera } \\
\text { Quercus tipo ilex } \\
\text { Rosaceae } \\
\text { Rosmarinus officinalis } \\
\text { Salix/ Populus sp. } \\
\text { Smilax aspera } \\
\text { Solanum sp. } \\
\text { Viburnum sp. } \\
\text { Fragmentos de cono de pino } \\
\text { Fragmentos de corteza } \\
\text { Tallos vegetales indeterminados } \\
\text { Indeterminable }\end{array}$ & $\begin{array}{r}1 \\
1 \\
2 \\
1 \\
199\end{array}$ & 123 & $\begin{array}{r}1 \\
1 \\
2 \\
1 \\
322 \\
\\
4 \\
\\
2 \\
2\end{array}$ & $\begin{array}{l}0,28 \\
0,86 \\
1,15 \\
\\
0,28 \\
0,28 \\
0,57\end{array}$ & $\begin{array}{r}5 \\
230 \\
5 \\
12 \\
2 \\
1 \\
\\
1 \\
4 \\
6 \\
3 \\
\\
2 \\
\\
274\end{array}$ & $\begin{array}{r}1,82 \\
83,94 \\
1,82 \\
4,37 \\
0,72 \\
0,36 \\
\\
0,36 \\
1,45 \\
2,18 \\
1,09 \\
0,72 \\
100\end{array}$ & $\begin{array}{r}1 \\
1 \\
3 \\
4 \\
2 \\
1 \\
1 \\
7 \\
1 \\
552 \\
5 \\
16 \\
2 \\
3 \\
2 \\
1 \\
4 \\
7 \\
2 \\
3 \\
\\
2 \\
1 \\
621\end{array}$ & $\begin{array}{r}0,16 \\
0,16 \\
0,48 \\
0,64 \\
0,32 \\
0,16 \\
0,16 \\
1,12 \\
\\
88,88 \\
0,80 \\
2,57 \\
0,32 \\
0,48 \\
0,32 \\
0,16 \\
0,64 \\
1,12 \\
0,32 \\
0,48 \\
\\
0,32 \\
\\
100\end{array}$ \\
\hline
\end{tabular}

Tab. 2. Taxones identificados en valores absolutos y relativos en las unidades estratigráficas de la fase II de Terlinques. Las Ues 1061 y 1066 corresponden a los niveles de derrumbe, mientras que la Ue 1048 es interpretada con un paquete sedimentario de acondicionamiento. Las categorías taxonómicas se presentan siguiendo el orden alfabético y la nomenclatura propuesta en Flora Europaea.

guen Rosmarinus officinalis, las leguminosas, $T a$ marix sp., Arbutus unedo, cf. Olea europaea, cf. Pistacia lentiscus, las monocotiledóneas, y, finalmente, en mucha menor proporción, Fraxinus sp., Phyllirea/Rhamnus, Erica sp., Cistus sp., Salix/Populus, Juniperus sp., Asparagus sp., Smilax aspera, Rosaceae y Solanum sp., y algunos fragmentos de Chenopodium sp.

El análisis antracológico también ha puesto en evidencia diferencias en las frecuencias relativas de las especies para cada una de las muestras, especialmente en lo que respecta a los valores del pino carrasco. Sin embargo, si tenemos en cuenta el contexto de procedencia estas diferencias se minimizan. En el conjunto de las unidades estudiadas de la fase I, por ejemplo, incluida la Ue 1041, el pino carrasco constituye solamente el $52,04 \%$; en la fase II el porcentaje asciende hasta el $88,88 \%$, frecuencia que se mantiene durante la III fase con el 75,36 \%. Estos resultados podrían llevarnos a errores interpretativos si no tuviésemos presente que una de las unidades de la fase I, la Ue 1041, corresponde al relleno de una estructura de combustión (Ue 2041) o que en la Ue 1009 se documentaron diversos puntos con concentración de artefactos de madera entre los que debemos individualizar un conjunto de ramas apuntadas de tarajal y acebuche (conjunto resalte Ue 1012) así como diversas varitas de fresno y viburno empleadas como husos y localizados en el interior del saco de esparto n. ${ }^{\circ} 1$ (Tab. 1). De modo que al excluir de la fase I la Ue 1041 (relleno de estructura de combustión) y los conjuntos señalados observamos que en las unidades interpretadas como derrumbe el pino carrasco representa el 84,88\%, Quercus ilex/Quercus coccifera un $4,73 \%$ y Rosmarinus officinalis el $4,37 \%$.

Por otro lado, las unidades 1048 y 1106 de las fases II y III, respectivamente, corresponden a 


\begin{tabular}{|c|c|c|c|c|c|c|c|c|c|c|}
\hline & $\begin{array}{c}\text { De- } \\
\text { rrumbe } \\
\text { UH 5 } \\
1052 \\
\end{array}$ & $\%$ & \begin{tabular}{|c} 
De- \\
rrumbe \\
UH 6 \\
1068 \\
\end{tabular} & $\%$ & $\begin{array}{c}\text { De- } \\
\text { rrumbe } \\
\text { UH 7 } \\
1073 \\
\end{array}$ & $\%$ & 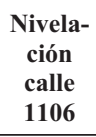 & $\%$ & TOTAL & $\%$ \\
\hline TAXONES & & & & & & & & & & \\
\hline Angiosperma & 4 & 1,40 & 1 & 0,48 & & & 35 & 4,31 & 40 & 2,71 \\
\hline Arbutus unedo & 2 & 0,70 & & & & & 7 & 0,86 & 9 & 0,61 \\
\hline Chenopodium sp. & 1 & 0,35 & & & & & & & 1 & 0,07 \\
\hline Erica sp. & & & & & & & 2 & 0,27 & 2 & 0,14 \\
\hline Fraxinus sp. & & & & & & & 2 & 0,27 & 2 & 0,14 \\
\hline Leguminosa & 1 & 0,35 & & & 3 & 1,73 & 1 & 0,12 & 5 & 0,33 \\
\hline Monocotiledónea & 2 & 0,70 & 1 & 0,48 & & & & & 3 & 0,20 \\
\hline Olea sp. & & & & & & & 1 & 0,12 & 1 & 0,07 \\
\hline Oleaceae & & & & & & & 1 & 0,12 & 1 & 0,07 \\
\hline Pinus halepensis & 251 & 89 & 200 & 96,15 & 162 & 93,64 & 612 & 75,36 & 1.225 & 83,05 \\
\hline Pistacia $\mathrm{sp}$. & 1 & 0,35 & & & & & 1 & 0,12 & 2 & 0,14 \\
\hline cf. Pragmitis & 1 & 0,35 & & & & & & & 1 & 0,07 \\
\hline Quercus ilex $/ Q$. coccifera & 6 & 2,12 & 2 & 0,96 & 5 & 2,89 & 93 & 11,45 & 106 & 7,18 \\
\hline Rosaceae & & & & & & & 7 & 0,86 & 7 & 0,47 \\
\hline Rosmarinus officinalis & 4 & 1,40 & 4 & 1,92 & 3 & 1,73 & 22 & 2,70 & 33 & 2,23 \\
\hline Salix/Populus sp. & & & & & & & 2 & 0,27 & 2 & 0,14 \\
\hline Viburnum sp. & & & & & & & 2 & 0,27 & 2 & 0,14 \\
\hline Indeterminable & 9 & 3,19 & & & & & 24 & 2,95 & 33 & 2,23 \\
\hline Total & 282 & 100 & 208 & 100 & 173 & 100 & 812 & & 1.475 & 100 \\
\hline
\end{tabular}

Tab. 3. Taxones identificados en valores absolutos y relativos de las unidades estratigráficas estadísticamente significativas de la fase III de Terlinques, correspondientes a estratos de derrumbe de las unidades habitacionales $n .{ }^{\circ} 5$ (Ue 1052), 6 (Ue 1068), 7 (1073) y el paquete de nivelación de la calle (Ue 1106). Las categorías taxonómicas se presentan siguiendo el orden alfabético y la nomenclatura propuesta en Flora Europaea.

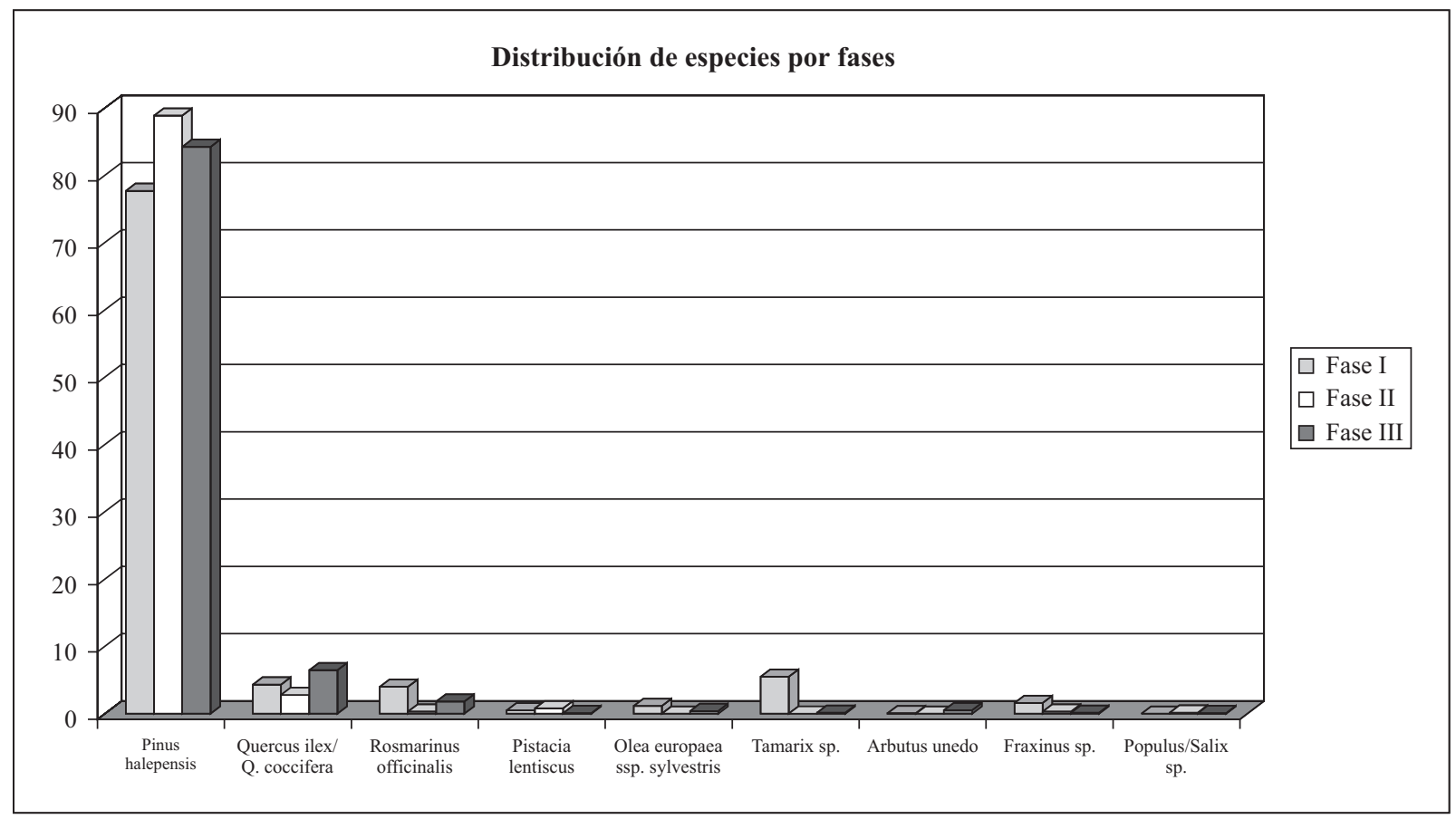

Fig. 3. Distribución porcentual de las principales especies reconocidas por fases en Terlinques, sin excluir ninguna de las unidades estratigráficas analizadas y sin diferenciar atendiendo a su interpretación. 


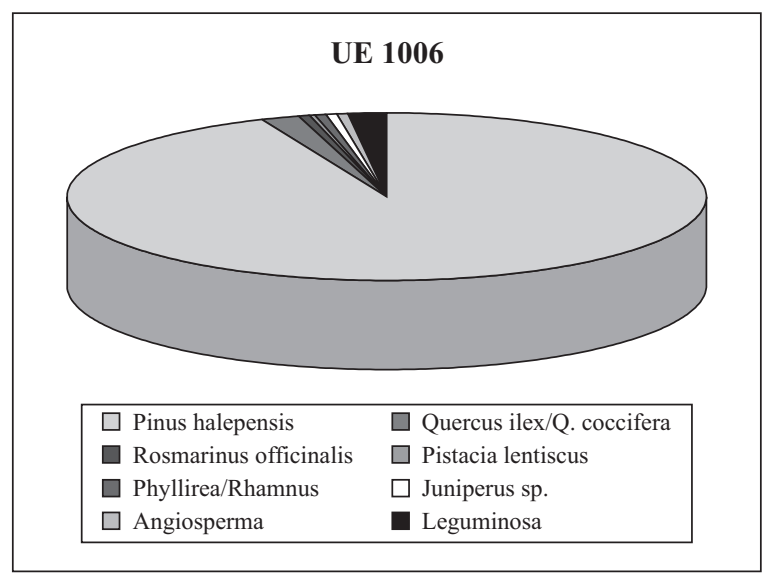

Fig. 4. Representación porcentual de especies en la Ue 1006 de la fase I de Terlinques interpretada como estrato de derrumbe.

paquetes de regulación donde la variedad de taxones es algo mayor que en los paquetes de derrumbe. Mientras los porcentajes de pino carrasco en las Ues 1048 y 1106 alcanzan los 83,94\% y $75,36 \%$ respectivamente, en los paquetes de derrumbe éstos superan el $90 \%$. De la misma forma, si exclusivamente tomásemos en consideración la unidad 1006, correspondiente a la capa de derrumbe de la unidad habitacional 1 de la fase I, el pino carrasco alcanzaría valores superiores al $93 \%$ (Fig. 4).

Estos valores son similares a los registrados en los estudios antracológicos realizados en yacimientos coetáneos del ámbito regional como la Lloma de Betxí (Grau 1998: 235), Castellón Alto (Rodríguez y Ruiz 1995: 171) o el corte 41 de Fuente Álamo (Carrión Marco 2004: 483).

\section{INTERPRETACIÓN DE LOS RESULTADOS}

En Terlinques, aunque es indiscutible que numerosos carbones tienen un valor paleoetnobotánico (Machado et al. 2004), otros son indicativos de las formaciones leñosas existentes en las cercanías del yacimiento. La lectura paleoecológica de este registro es un aspecto esencial en la comprensión del yacimiento arqueológico, aunque ésta se base más en datos cualitativos que cuantitativos (presencia o ausencia de especies y no tanto en los porcentajes de representatividad), y se apoye en los datos de otros estudios paleoambientales y económicos, tales como los análisis palinológicos, ecológicos y carpológicos.

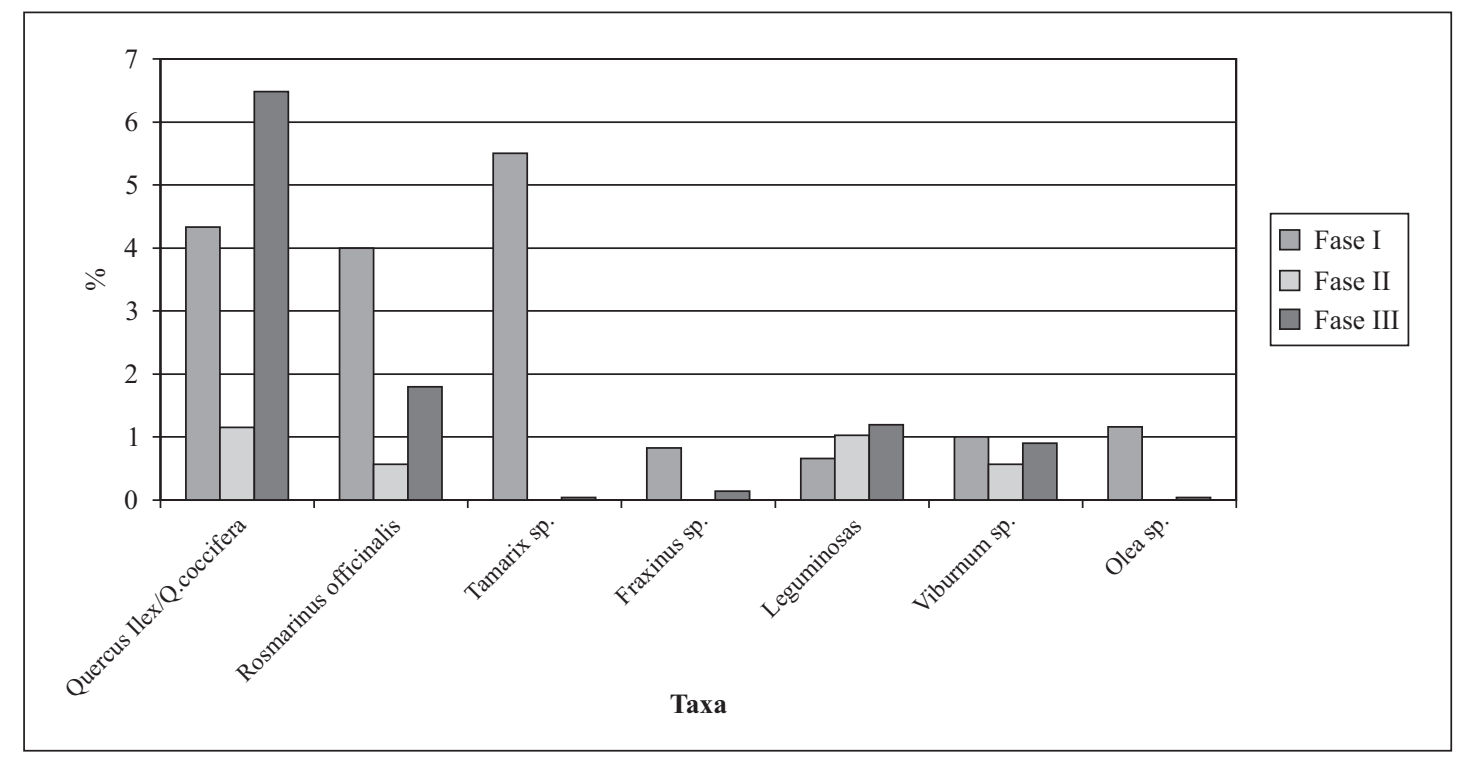

Fig. 5. Distribución por fases de las especies identificadas en Terlinques con porcentajes superiores al 0,5\%, excepto Pinus halepensis. 


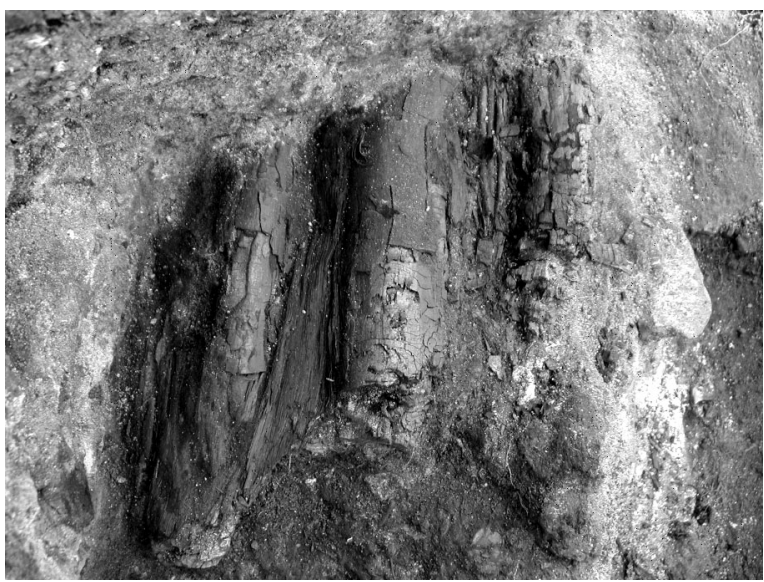

Lám. IV. Detalle de los troncos de la techumbre de la unidad habitacional $n .^{\circ} 1$ caídos de Terlinques sobre el pavimento Ue 1012 (Fase I).

El análisis antracológico ha puesto en evidencia un conjunto florístico característico de los bosques termo/mesomediterráneos. Los taxones característicos son Pinus halepensis (pino carrasco), Quercus ilex/Q. coccifera (encina, coscoja), Pistacia lentiscus (lentisco), Arbutus unedo (madroño), Juniperus sp. (enebro), Olea europaea (acebuche), Fraxinus sp. (fresno), Salix/Populus sp. (sauce), Erica sp. (brezo), Cistus sp. (jaras), Rosmarinus officinalis (romero), Asparagus sp. (esparraguera), Smilax aspera (zarzaparrilla) y Viburnum sp. (viburno), entre otros (Tab. 1, 2 y 3).

Pinus halepensis aparece en todas las unidades estratigráficas, en las capas de derrumbe y de acondicionamiento, en el interior de las estructuras y entre los carbones dispersos. El dominio de este taxón puede explicarse, como hemos dicho, fundamentalmente, porque con su madera se fabricaron las vigas, largueros y otros elementos constructivos (Machado et al. 2004), pero también porque sus ramas se usaron como combustible, como atestigua el contenido del hogar (Ue 1041 de la fase I) y los carbones dispersos en paquetes de regularización (Ue 1106 de la fase III), donde esta especie representa el 75,36 \%. En esta última unidad sedimentaria que es interpretada como un nivel de acondicionamiento del suelo de una zona de paso o calle entre las unidades habitacionales de la fase III, la presencia de este taxón se explica como respuesta a una práctica doméstica: la limpieza de los hogares y el empleo de detritus como materia para regularizar las zonas de paso exteriores.
Si de acuerdo con Chabal (1998) partimos de la idea que los carbones dispersos ofrecen una imagen más o menos representativa de las vegetación leñosa de una localidad, tenemos que admitir que este porcentaje responde a una realidad ecológica en la que el pino carrasco formaba parte, mayoritariamente, del entorno inmediato al asentamiento. Si esta idea fuese acertada sería poco probable que la serie climática que define actualmente el paisaje vegetal de esta comarca, Quercetum rotundifoliae arenarietosum intrincati (Alonso 1996: 235), pudiera definirlo durante la Edad del Bronce, ya que entre el 2100 y el 1500 AC de acuerdo con el antraco-análisis, Quercus sp. y otros elementos florísticos de esta serie climática están poco representados o ausentes. Tampoco tienen protagonismo actualmente las especies características de las alianzas fitosociológicas Quercion ilicis y Oleo-Ceratonion (Rivas Goday y Rivas Martínez 1971). El Oleo-Ceratonion tradicional se caracteriza por elementos termófilos tales como el algarrobo (Ceratonia siliqua L.), el palmito (Chamaerops humilis L.), el acebuche (Olea europaea L. var. sylvestris Brot.), etc., y faltan o son raras las especies propias del Quercion ilicis (Quercus ssp. ilex y Quercus suber L.), las encinas o el alcornoque. En este mismo sentido, apuntan los estudios palinológicos efectuados en distintos depósitos endorreicos de la cuenca del Vinalopó (Burjachs et al. 1997; Giralt et al. 1999; Yll et al. 2003).

En Terlinques, la presencia de Quercus sp. es escasa y se relaciona, principalmente, con el entramado de la cubierta de los edificios y con su utilización como leña. También son raras

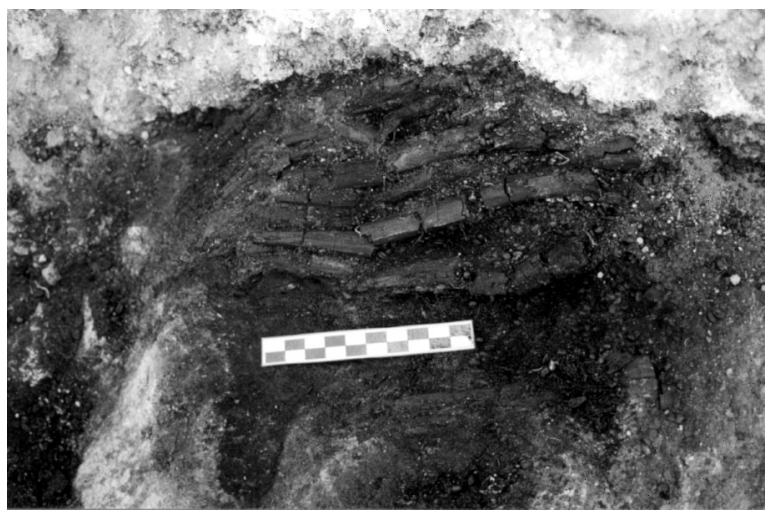

Lám. V. Ramas apuntadas de Olea europaea ssp. silvestris y Tamarix sp. documentadas sobre el pavimento 1012, fase I de Terlinques. 
las especies del bosque mediterráneo esclerófilo (Olea europaea ssp. silvestris, Pistacia lentiscus, Rhamnus sp., Juniperus sp., etc.) exceptuando algunos elementos propios del matorral, como Rosmarinus officinalis, que puede indicarnos la degradación de las formaciones arbóreas. Si los Quercus sp. y otras especies arbóreas arbustivas características del piso mediterráneo o esclerófilo no eran abundantes en el corredor de Villena durante la Edad del Bronce ¿qué comunidad o comunidades vegetales pudieron definir el paisaje?, ¿cuáles serían las áreas de distribución de Quercus sp. y de Pinus halepensis? y ¿cuáles son las exigencias ecológicas de estas especies?

Los dominios de la encina Quercus ilex L. pueden considerarse relativamente húmedos en el triple sentido de que requieren una pluviosidad no escasa, rara vez inferior a $600 \mathrm{~mm}$, una sequía estival corta y una humedad relativa no muy baja. La encina de hoja ancha, carrasca o encina carrasca, Quercus rotundifolia Lam., soporta pluviosidades menores incluso ligeramente inferiores a $400 \mathrm{~mm}$ y una sequía estival más prolongada, con mínimos de humedad relativa más bajos. La principal diferencia entre ambas encinas es el carácter más xerófilo de Quercus rotundifolia.

El límite inferior y superior de la encina no va ligado a un cambio de piso bioclimático. No hay un piso de la encina y un piso de las maquias termofilas. El paso de los bosques de encinas o alcornoques a los espinales va ligado al balance de humedad, al paso de un ombroclima subhúmedo o seco al de un ombroclima semiárido, y este paso puede producirse, tanto dentro del piso termomediterráneo, como dentro del mesomediterráneo. También la carrasca puede rebasar el límite mesosupramediterráneo.

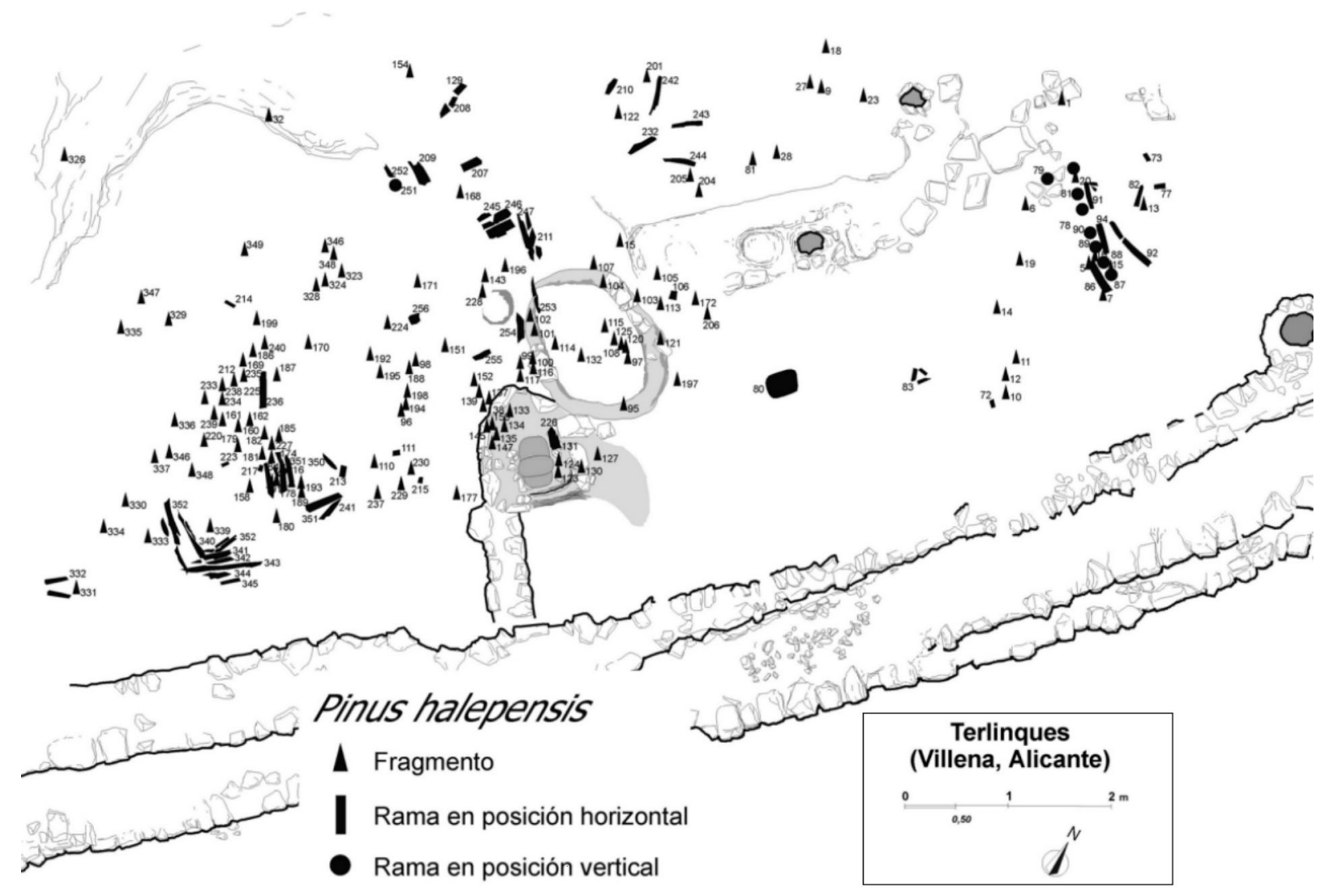

Fig. 6. Distribución de Pinus halepensis en la unidad habitacional n. ${ }^{\circ} 1$ de la fase I de Terlinques. 
En conclusión, Quercus ilex ssp. ilex (la encina) es una especie con gran amplitud ecológica, pero es exigente en cuanto a la humedad. En el área de Quercus ilex, la encina ocupa los sustratos calizos y el alcornoque los silíceos. La encina carrasca ocupa las crestas y partes altas de las laderas y el quejigo los suelos más profundos de la parte inferior y valles (Ferreras 1987). El encinar se desarrolla en condiciones óptimas entre 500 $\mathrm{mm} / 600 \mathrm{~mm}$ de precipitaciones medias anuales. Hoy en Villena los valores de las precipitaciones medias fluctúan entre 200/375 mm anuales.

Pinus halepensis (pino carrasco) es una especie con gran amplitud geográfica. En la Península Ibérica se extiende prácticamente desde el nivel del mar hasta los $1.600 \mathrm{~m}$ s.n.m. Dentro de este rango altitudinal ocupa principalmente las zonas basales xerotérmicas y de altitudes medias, con un óptimo por debajo de los $800 \mathrm{~m}$. de altitud. No es exigente en cuanto a las precipitaciones puesto que aparece, tanto en localidades que reciben menos de $400 \mathrm{~mm}$ de precipitaciones anuales (150 $\mathrm{mm}$ totales en Cartagena), como en otras con valores superiores a $1.000 \mathrm{~mm}$. Es la especie arbórea mejor adaptada a la sequía. Uno de los factores climáticos que limita el área de esta especie es la temperatura (Blanco et al. 1998). Por tanto, los pinares de pino carrasco constituyen formaciones naturales en el área mediterránea sobre sustratos margosos, sobre suelos pobres en nutrientes y riesgo de sequedad.

En localidades de ambiente seco y continental, como podríamos calificar la comarca de Villena, el pinar se localizaría en exposiciones sur o zonas edáficas poco favorables para el encinar, pudiendo en algunas zonas mezclarse con este último. Estos pinares se extienden entre 500 y $800 \mathrm{~m}$ de altitud, sobre sustratos margosos, calcáreos y yesos. Se trataría de bosques aclarados con un sotobosque termófilo donde pueden ser abundantes la coscoja, el enebro, el lentisco, el romero, también la jara, la salvia, el tomillo, el rabo de gato y entre las especies herbáceas, el esparto.

Si durante la Edad del Bronce las condiciones climáticas eran similares a las actuales es poco probable que las encinas caracterizaran florísticamente este territorio, ya que las exigencias ecológicas (humedad) de esta especie no son adecuadas para su desarrollo. En cambio, sí eran favorables al desarrollo de las especies de la asociación Quercetum rotundifoliae (donde el pino carrasco sería dominante) o para el desarrollo de un pinar de carácter mixto, donde el pino carrasco pudo compartir el espacio con Quercus rotundifolia, Quercus coccifera y otras especies termófilas.

No obstante, no podemos descartar que las condiciones bioclimáticas de esta comarca durante la Edad del Bronce fueran un poco diferentes a las actuales, como se ha podido comprobar en otros contextos geográficos mediterráneos (Heinz et al. 2004: 626).

Con independencia de los condicionantes climáticos, otro aspecto que incide en el desarrollo de las comunidades vegetales es la acción antrópica. Los incendios para renovar los pastizales y poner tierras en cultivo, la presión de los rebaños, la tala, etc., generarían cambios en los suelos. Los procesos de erosión que implica el desarrollo de toda esta serie de prácticas, pudieron conllevar la regresión del encinar y el crecimiento del pinar y del matorral. Un factor que podría explicar por qué en contextos arqueológicos alejados como La Lloma de Betxí (Grau, 1998) y Castellón Alto (Rodríguez 1995), dos yacimientos coetáneos, que se localizan a más de $150 \mathrm{~km}$ de distancia de Terlinques, el pino carrasco también es dominante.

Otros análisis antracológicos (4) y polínicos vienen en apoyo a las ideas expuestas. En este sentido, en el yacimiento calcolítico de Torreta-El Monastil (Elda) (Jover 2006), localizado a menos de $20 \mathrm{~km}$ al sur de Terlinques, constatamos que el Pinus halepensis es dominante con un porcentaje del 61,4\%. En menor medida aparecen Quercus ilex/Q. coccifera $-11 \%-$, Arbutus unedo -4,5\%-, Juniperus sp., Olea europaea ssp. sylvestris, Pistacia lentiscus, Salix sp. y Daphne. También, en el yacimiento de la Edad del Bronce de Barranco Tuerto (Jover y López 2005), coetáneo a las fases II y III de Terlinques y situado a unos $7 \mathrm{~km}$ del mismo, vuelve a confirmarse la presencia de pino carrasco en la cubeta de Villena. Y lo mismo podemos plantear para el asentamiento de la Edad del Bronce de la Lloma Redona (Monforte del Cid), sincrónico a la fase II de Terlinques y situado a algo más de $30 \mathrm{~km}$ al sur, donde el análisis antracológico de una muestra

(4) A pesar que la comarca del Alto Vinalopó ofrece un alto potencial arqueológico y los registros son ricos en carbones, los estudios antracológicos siguen siendo escasos e insuficientes para permitir una construcción hipotética de la dinámica vegetal.

T. P., 66, N. ${ }^{\circ} 1$, enero-junio 2009, pp. 75-97, ISSN: 0082-5638 doi: 10.3989/tp.2009.09013 


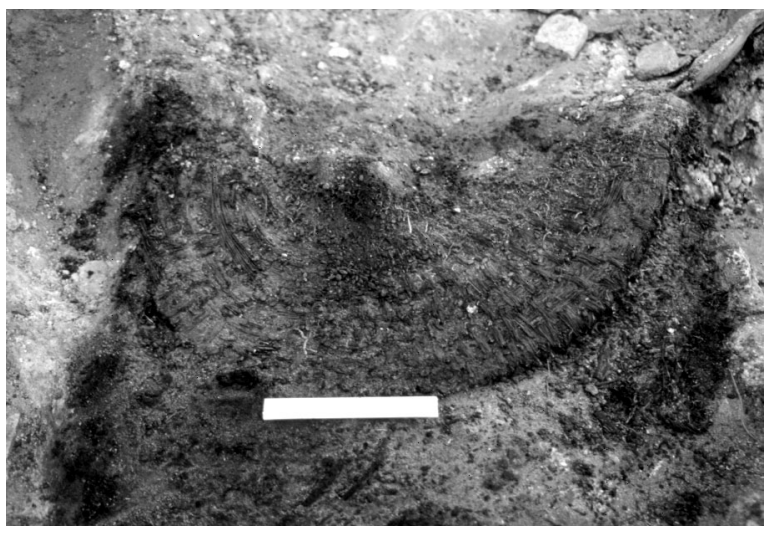

Lám. VI. Detalle de la tapadera del capazo de estiba n. ${ }^{\circ}$, con cereales y malas hierbas, documentado en la Ue 1009 de la fase I de Terlinques.

reducida, revela nuevamente el dominio de Pinus halepensis, con un porcentaje del 88,90\% frente a Quercus sp. y Rosaceae (5).

Del mismo modo, son varias las columnas polínicas disponibles en depósitos endorreicos de la cuenca del Vinalopó. En primer lugar, el registro polínico realizado en la Laguna de Villena, situada a escasa distancia de Terlinques, muestra la existencia del pino en la zona desde el intervalo Tardiglaciar-Holoceno, 10300 y 9400 BP (Yll et al. 2003). En la Laguna de Salinas, situada unos kilómetros más al sur, los estudios realizados muestran que a finales del Mesolítico, sobre el $7500 \mathrm{BP}$, se sucede una fase de aridez que perdurará hasta el Bronce Final, 3000 BP, avalado por la escasa sedimentación y por la predominancia del pino en el paisaje (Giralt et al. 1999). En el depósito de Elche, desde los inicios del Neolítico se detecta un cambio estructural de la vegetación, sin que varíe la cubierta arbórea. En concreto, se documenta un descenso de todos los taxones, excepto de Juniperus y Pinus que aumentan (Burjachs et al. 1997: 387).

La presencia de taxa mesotermófilos, incluyendo caducifolios (Quercus, Carpinus, Salix) y esclerófilos (Quercus, Olea, Pistacia, Phillyrea, Rhamnus, Cistus) durante el intervalo glaciar sugiere la existencia de refugios adyacentes para la flora templada y mediterránea. Se trataría de pequeñas poblaciones dispersas por valles abri-

(5) Machado Yanes, M.C. 2001: Estudio de una muestra de carbones procedentes del yacimiento de la Edad del Bronce de la Lloma Redona (Monforte del Cid, Alicante). Universidad de La Laguna. La Laguna. Informe inédito. gados en el interior de los macizos montañosos adyacentes (Carrión, 2002, en Yll et al. 2003:70).

Para estos autores, "la falta de colonización tardiglaciar y postglaciar por parte de las frondosas podría ser más un fenómeno frecuente que una excepción. La consecuencia inmediata de esta prevalencia es que muchos paisajes actuales dominados por el pino no deberían ser contemplados como antropogénicos, sino más bien como el resultado de una inercia milenaria cuyo origen se remonta a la última glaciación" (Blanco et al. 1997, en Yll et al. 2003: 70). En este orden de ideas otros autores han destacado que la colonización por Quercus no siempre se justifica como respuesta al cambio climático durante la terminación glaciar, sino a menudo se puede generar como consecuencia de perturbaciones naturales - principalmente- o producidas por los seres humanos, siendo el fuego un factor de primer orden (Carrión 2001).

Por tanto, los datos palinológicos muestran que el pino carrasco fue abundante en la cuenca del Vinalopó al menos entre el 10300 BP y el 3000 BP (6).

Por otro lado, desde la ecología se ha realizado otra aproximación a esta problemática haciendo uso de modelos matemáticos generados mediante redes neuronales a fin de conocer la potencialidad de los encinares y alcornocales en la Península Ibérica y, en particular, en la región levantina. En estos trabajos, las variables bioclimáticas empleadas como predictores son: altitud, continentalidad, insolación, precipitación total, temperatura media anual, temperatura media de las mínimas del mes más frío y temperatura media de las máximas del mes más cálido, con una resolución de $10 \mathrm{~km}$. Los resultados muestran patrones de respuesta diferente para las dos formaciones. Mientras que para la encina se simula un área potencial continua y extensa, para el alcornoque se obtiene un área fragmentada y restringida, que se ajusta bastante a su presencia actual. La principal discrepancia del modelo con es-

(6) No obstante, en la interpretación de los diagramas palinológicos tenemos que tener en cuenta que las fabaceas en general y en particular Quercus sp. son entomófilas y no producen mucho polen; al contrario que los pinos que producen grandes cantidades; por esa razón los Quercus pueden estar subrepresentados en los diagramas polínicos véase Burjachs i Casas, F. 1985: Aplicació de l'analisi pol-linic al jaciment arqueológic de "La Cova 120" (Alta Garrotxa, Catalunya). Tesis de Licenciatura. Universitat Autònoma de Barcelona. 


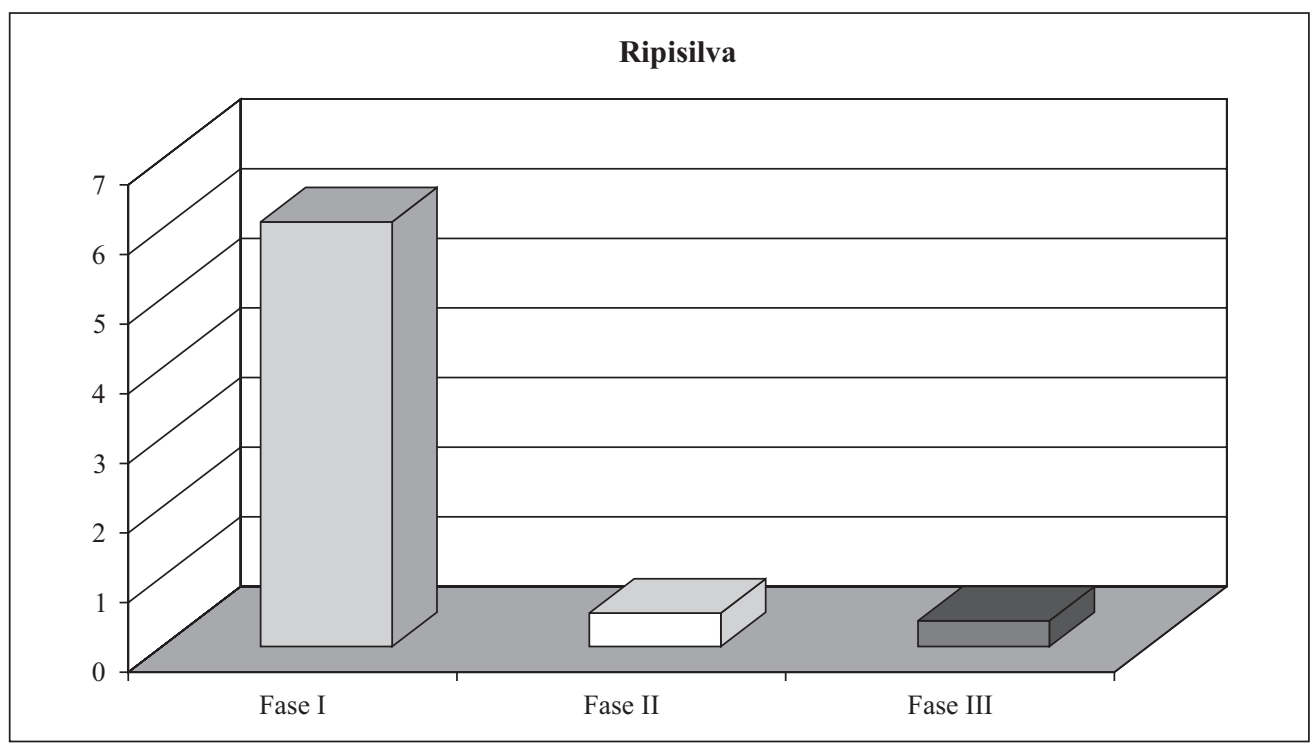

Fig. 7. Representación porcentual por fases de la ripisilva en el yacimiento de Terlinques. Las diferencias de representación entre la fase I y el resto se explican por documentación en la primera de conjuntos de instrumentos sobre el pavimento de ocupación y de una estructura de combustión con combustible.

quemas de vegetación potencial anteriores radica en la ausencia de encinares y alcornocales en zonas térmicas del Levante y sur peninsular (Benito et al. 2003).

\section{DISCUSIÓN}

Terlinques es un asentamiento de la Edad del Bronce ocupado entre c. 2100 y 1500 AC en el que han podido reconocer tres fases de ocupación. Está ubicado en el centro de un espacio geográfico privilegiado como es el corredor del Vinalopó. Este espacio constituye una falla transversal a las alineaciones montañosas béticas, que conecta diversos territorios, la Meseta a través del corredor de Almansa y la región murciano-almeriense y granadina, con quienes comparte influencias climáticas (continentalidad y aridez), florísticas y culturales.

Los estudios antracológicos (Machado et al. 2004) y paleocarpológicos (Precioso y Rivera 1999) efectuados revelan el cambio de uso de los territorios circundantes y una antropización de las tierras cercanas al poblado, en especial de las laderas y las orillas de la Laguna de Villena situada a escasa distancia.
La alteración del medio vegetal potencial que probablemente se inició desde el Neolítico, como consecuencia de la ocupación y puesta en explotación de las tierras del Vinalopó (Guilabert et al. 1999; Jover y López 1999; 2005), se intensificaría durante el desarrollo de la Edad del Bronce, dado el especial aumento demográfico que se constata (Jover y López 1999), siendo más intenso después de 500 años de ocupación continuada de Terlinques -fase III de Terlinques- así como de buena parte de los cerros que jalonan todo el valle. Un período de tiempo suficientemente largo para que se manifiesten cambios significativos en la vegetación (Badal 1995).

Los datos antracológicos permiten corroborar una diversificación de las áreas de recogida de la leña, desde las ramblas que discurren por los fondos de valle y corredores, el cauce del río Vinalopó y la Laguna de Villena, donde serían frecuentes especies como el Tamarix sp., Salix/Populus sp. y las monocotiledóneas, hasta las elevaciones montañosas con altitud superior a $800 \mathrm{~m}$, como las cercanas sierras del Castellar y de Salinas.

Esta gestión, que en un primer momento supuso un control de los recursos forestales y del pinar, forma parte de la racionalidad económica de toda comunidad campesina (Toledo 1993). El aprovechamiento del bosque se integraría dentro 


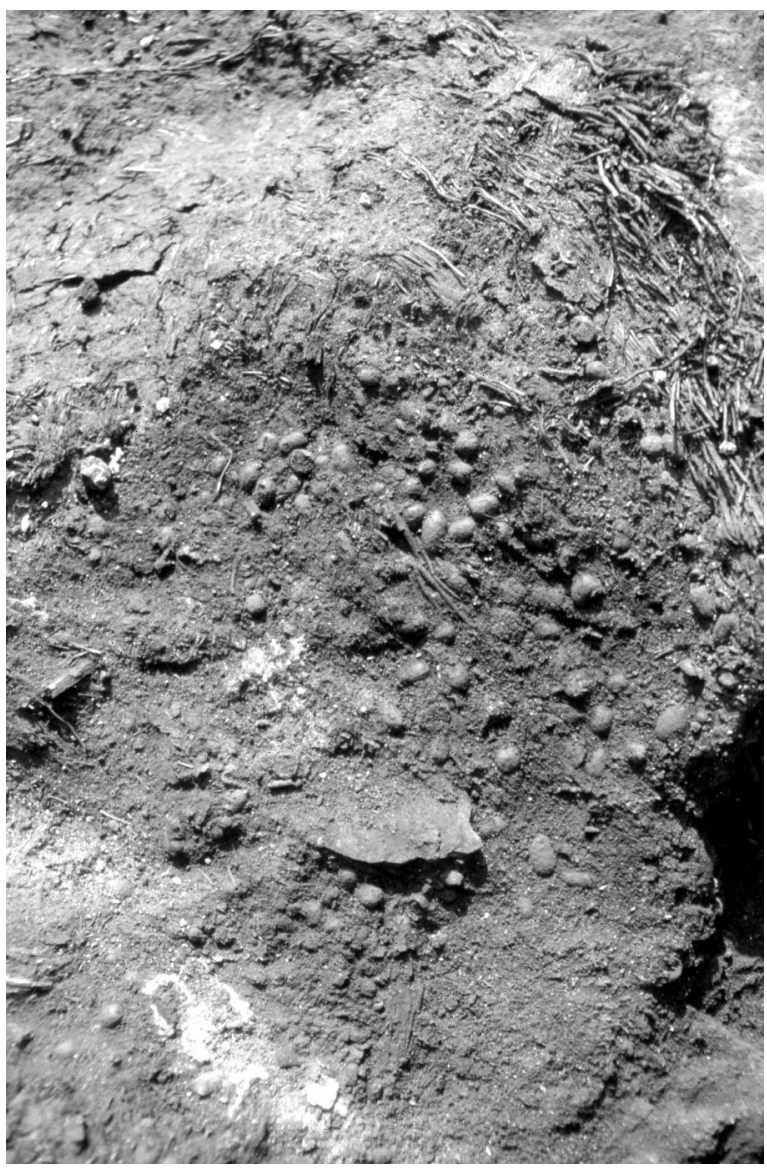

Lám. VII. Detalle de estiércol en uno de los sacos de esparto en la unidad habitacional $n .^{\circ} 1$, fase I de Terlinques.

de un sistema de explotación del territorio, en el que la silvicultura (el aprovechamiento de recursos forestales y cinegéticos), la agricultura y la ganadería asegurarían el mantenimiento del grupo (7). A partir de c. 1700 AC -Fase III de Terlinques- constatamos toda una serie de cambios tanto en los espacios habitados, como en el territorio. Las viviendas se redujeron considerablemente en tamaño, cambió la distribución y características de las áreas de actividad y probablemente se produjo un significativo aumento de-

(7) En estos momentos en los diversos asentamientos de características similares a Terlinques existentes en la zona se establecería una gestión integral de los recursos disponibles dentro de un área de explotación en torno a los $10 \mathrm{~km}^{2}$. Esto permitiría una rotación sobre todo para los cultivos de barbecho e, incluso, una zona destinada a monte en cada una de las áreas de explotación de cada poblado (Jover 1999; Jover y López 1999; 2004). mográfico, observable en la multiplicación del número de asentamientos en el territorio. Para este momento, exclusivamente en la cubeta de Villena, se alcanzó una cifra superior a 60 asentamientos y superior a 150 en toda la cuenca del Vinalopó (Jover y López Padilla 2004).

Una mayor presión demográfica en el territorio supondría una mayor presión sobre los recursos y, en especial, sobre las comunidades vegetales existentes en el medio, aunque todavía no sabemos cómo pudieron afectar los cambios señalados a la gestión de la biomasa vegetal. Necesariamente se produciría un aumento de las tierras roturadas en los territorios inmediato a los poblados según indican los numerosos restos carpológicos (Precioso y Rivera 1999), aumentaría la acción pastoril y necesariamente generaría un retroceso del bosque, en particular de los matorrales termomediterráneos y de la ripisilva, como sugiere la correlación existente entre el descenso de las especies arbóreas, en particular Tamarix sp. y Salix sp. y el aumento del matorral, junto al uso de estiércol como combustible (Machado et al. 2004), aunque en este último caso, no podemos descartar su empleo en otros menesteres como aislamientos o protección contra insectos.

Los datos del antracoanálisis efectuado en Terlinques han permitido documentar que entre el 3800 BP y 3200 BP existirían diversas comunidades vegetales en su entorno. Una formación arbórea donde Pinus halepensis sería la especie dominante. Este pinar de carácter mixto se acompañaría por un conjunto de especies de porte arbóreo-arbustivo como Quercus sp., Olea sp. y Pistacia lentiscus en las laderas de solana, y Arbutus unedo en zonas más húmedas. Fraxinus ornus se desarrollaría en las crestas en las zonas de umbrías más húmedas. En estas zonas, también pudo localizarse la encina (Quercus ilex). El matorral, el romero (Rosmarinus officinalis), las leguminosas y la jara (Cistus sp.) que forman el sotobosque se localizarían en las laderas. La ripisilva cerca de la Laguna de Villena y otros cursos de agua con especies como Tamarix sp., Salix/Populus sp., Atriplex articulata, Arundo donax y otras monocotiledóneas. También identificamos Chenopodium sp. desarrollado sobre suelos ricos en sal.

Teniendo en cuenta las formaciones leñosas documentadas en Terlinques, las condiciones climáticas para la cubeta de Villena no parecen ha- 


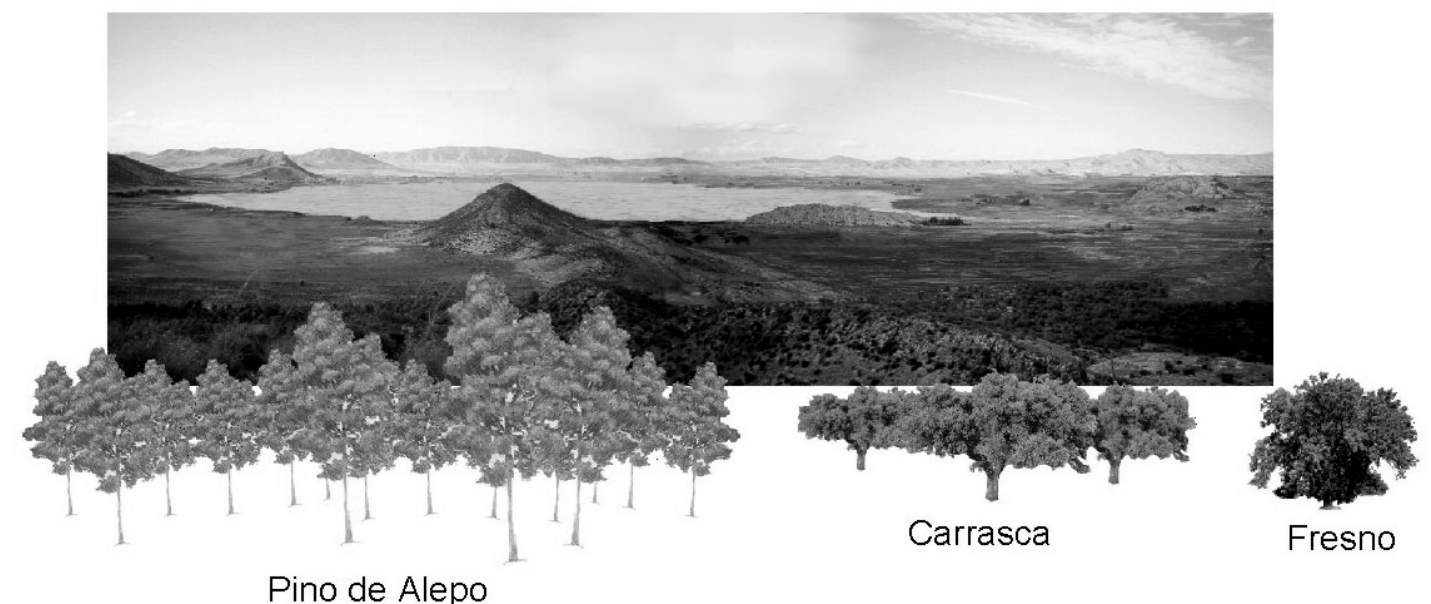

Lám. VIII. Representación hipotética del paisaje del entorno de la Laguna de Villena desde Terlinques durante la Edad del Bronce.

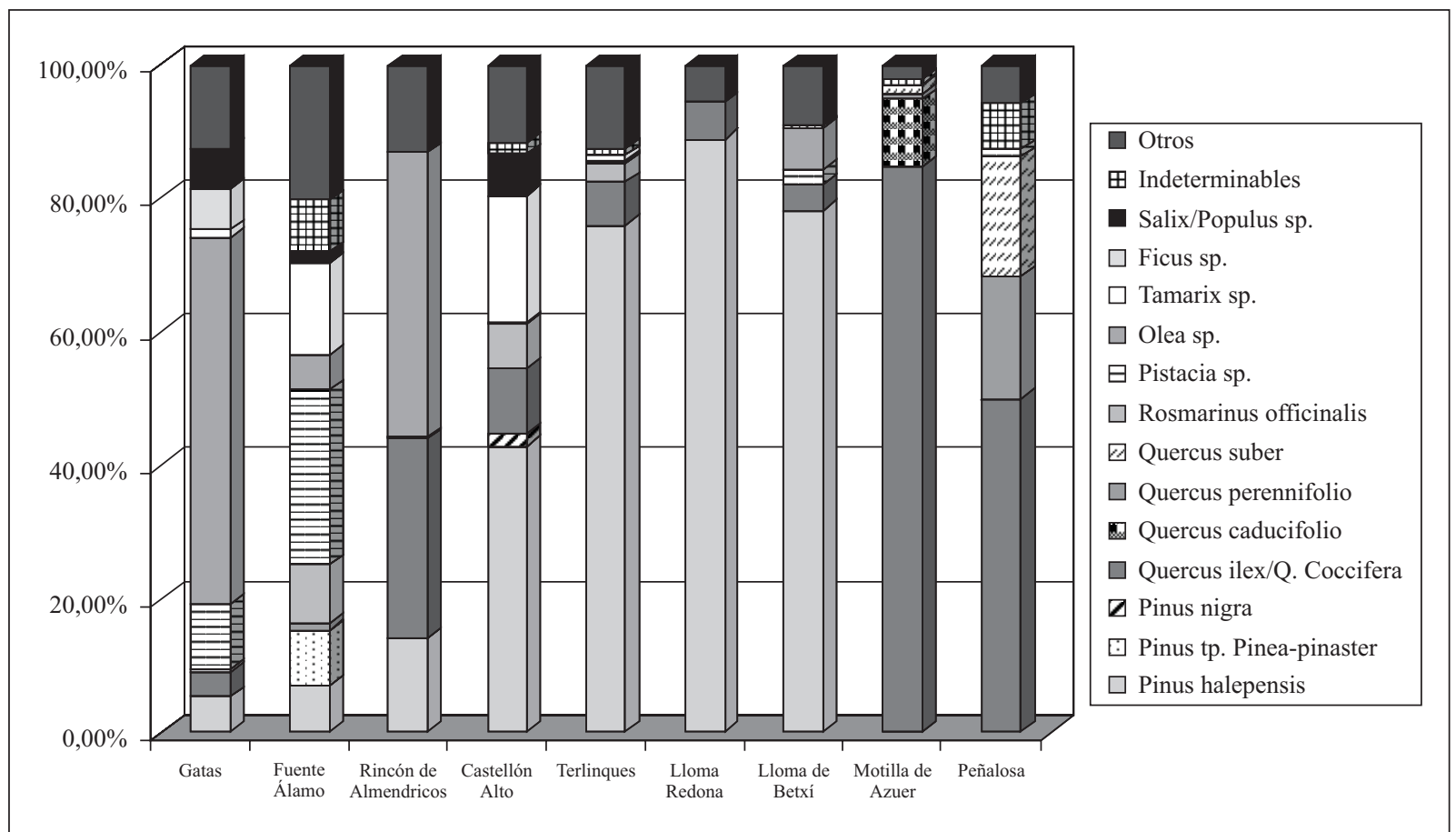

Fig. 8. Distribución porcentual de las principales especies (> $5 \%$ ) documentadas en los yacimientos de Gatas (niveles argáricos) (Gale 1999), Fuente Álamo (Carrión 2005), Rincón de Almendricos (Ayala 1991), Castellón Alto (Rodríguez et al. 1995; 1996), Terlinques, Lloma Redona (Machado, nota 5), Lloma de Betxí (Grau 1998), Motilla de Azuer (Rodríguez et al. 1999) y Peñalosa (Rodríguez 2000). 


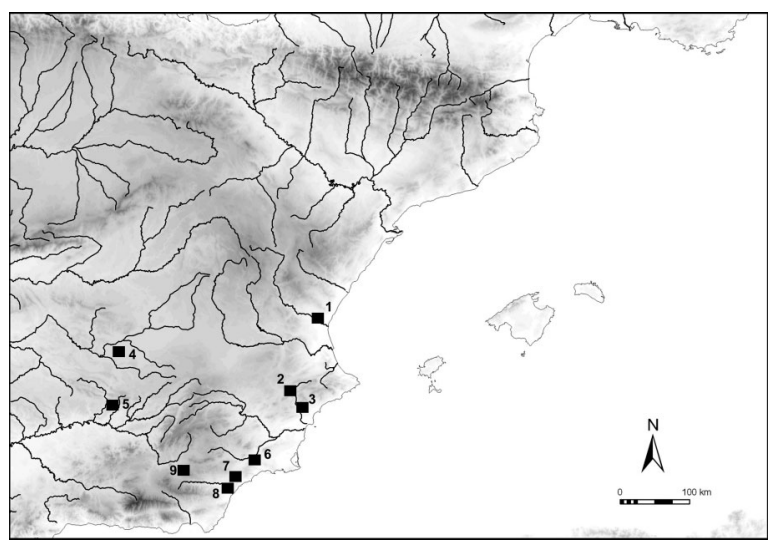

Fig. 9. Distribución de los yacimientos de la Edad del Bronce citados en el texto. 1.- Lloma de Betxí; 2.- Terlinques; 3.- Lloma Redona; 4.- Motilla de Azuer; 5.- Peñalosa; 6.- Rincón de Almendricos; 7.- Fuente Álamo; 8.- Gatas; 9.- Castellón Alto.

ber sido muy diferentes a las actuales, favorables al desarrollo de un pinar mixto y al matorral y poco favorable para el desarrollo del encinar.

Al mismo tiempo, a partir de los datos disponibles sobre la representatividad porcentual de las especies antracológicas registradas en diversos asentamientos coetáneos a Terlinques, ubicados en el cuadrante suroriental de la Península Ibéri$\mathrm{ca}$, podemos añadir algunas consideraciones a las ya sugeridas.

Mientras el conjunto documentado en Terlinques es muy similar a yacimientos como Lloma Redona (Monforte del Cid, Alicante), situado en el mismo corredor del Vinalopó, y a la Lloma de Betxí (Paterna, Valencia), situado en la cuenca del Turia (Pedro 1998), también es evidente que comparte cierta afinidad con Castellón Alto (Galera, Granada) (Rodríguez y Ruiz 1995, Rodríguez et al. 1996), aunque en este último las especies de ripisilva están mejor representadas. Esta diferencia se explica por la ubicación de Castellón Alto justo en la margen derecha de la vega del río Galera. Por otro lado, la gráfica también muestra cómo Terlinques tiene un espectro vegetal más alejado de yacimientos murcianos como Rincón de Almendricos (Ayala 1991) y almerienses como Fuente Álamo (Carrión 2004; 2005) y Gatas (Gale 1999), donde la presencia del pino carrasco es mucho menor y la Olea está mucho más extendida; y, por otro, está muy distanciado de yacimientos del interior peninsular como Motilla de Azuer (Rodríguez et al. 1999) o Peñalosa (Rodríguez Ariza 2000), donde el Pinus halepen- sis está totalmente ausente, las especies de ripisilva son muy escasas y se constata el dominio de los Quercus.

Por tanto, el actual gradiente latitudinal de biomasa vegetal, entre húmedo noreste y semiárido sureste persiste a lo largo del Holoceno, probablemente desde antes de la introducción de las actividades agropecuarias (Piqué 2006). A partir de los estudios antracológicos y palinológicos efectuados, podemos corroborar, en lo que respecta a la evolución del paisaje en el cuadrante suroriental de la Península Ibérica, que la biomasa vegetal en los últimos 10.000 años -excepto en los últimos 2.000-, parece haber estado condicionada por microciclos climáticos donde los grupos humanos han contribuido a la desertificación dentro de un proceso ya iniciado de desertización. Se trataría, por tanto, de un proceso de expansión de la aridez iniciado a partir del sureste peninsular y de su óptimo climático Holoceno (Burjachs et al. 1997: 392), sobre el que además incidiría la acción humana, especialmente en aquellos momentos en los que se constata una importante estabilidad y aumento poblacional como es la Edad del Bronce. La localización de Terlinques en un espacio donde convergen las influencias climáticas de las tierras meseteñas -en particular del corredor de Almansa- y del sureste hace de este territorio un espacio frontera.

En definitiva, consideramos que este trabajo puede contribuir al avance de las investigaciones realizadas en el cuadrante suroriental de la Península Ibérica, aunque es necesario seguir profundizando ante el escaso número de estudios antracológicos disponibles en un territorio que fue poblado desde antiguo. Su comparación con registros anteriores y otros sincrónicos permitirán avanzar sobre las cuestiones metodológicas señaladas y sobre el valor ecológico de las muestras.

\section{BIBLIOGRAFÍA}

Alonso Vargas, M.A. 1996: Flora y vegetación del Valle de Villena (Alicante). Generalitat Valenciana. Conselleria de Cultura, Educació i Ciència. Instituto de Cultura "Juan Gil-Albert". Alicante.

Ayala Juan, M.M. 1991: El poblamiento argárico de Lorca. Estado de cuestión. Ayuntamiento de Lorca. Real Academia Alfonso X El Sabio. Murcia. 
Badal García, E. 1995: “La vegetación carbonizada. Resultados antracológicos del País Valenciano". El Cuaternario del País Valenciano. Universidad de Valencia. Valencia: 217-226.

Benito Garzón, M.; Maldonado Ruiz, M.; Sánchez de Dios, R. y Sainz Ollero, H. 2003: "Predicción de la potencialidad de los bosques esclerófilos". Graellsia 59 (2-3): 345-358.

Burjachs, F.; Giralt, S.; Roca, J.R.; Seret, G. y Julià, R. 1997: "Palinología holocénica y desertización en el mediterráneo occidental". En J.J. Ibáñez, B.L. Valero y C. Machado (eds.): El paisaje mediterráneo a través del espacio y del tiempo. Implicaciones de la desertificación. Geoforma ediciones. Zaragoza: 379-394.

Buxó, R. 2006: "Paisajes culturales y reconstrucción histórica de la vegetación”. Ecosistemas 15 (1): 1-6.

Blanco Castro, E.; Casado González, E.; Costa Tenorio, M.; Escribano Bombín, R.; García Antón, M.; Génova Fuster, M.; Gómez Manzaneque, A.; Gómez Manzaneque, F.; Moreno Saiz, J.C.; Morla Juarista, C.; Regato Pajares, P. y Sainz Ollero, H. 1998: Los bosques ibéricos: una interpretación geobotánica. Ed. Planeta. Barcelona.

Carrión Marco, Y. 2004: “Análisis antracológico del yacimiento de Fuente Álamo (Cuevas de Almanzora, Almería): usos de la madera y paleovegetación”. En M. Hernández y L. Hernández (eds.): La Edad del Bronce en tierras valencianas y zonas $l i$ mitrofes. Ayuntamiento de Villena. Instituto alicantino de Cultura Juan Gil-Albert. Villena: 241-246.

Carrión Marco, Y. 2005: La vegetación mediterránea y atlántica de la Península Ibérica. Nuevas secuencias antracológicas. Trabajos Varios del Servicio de Investigación Prehistórica 104. Valencia.

Carrión, J.S. 2001: "Condicionantes de la respuesta vegetal al cambio climático. Una perspectiva paleobiológica". Acta Botánica Malacitana 26: 157-176.

Carrión, J.S. 2002: "Patterns and processes of Late Quaternary enviromental change in a montane region of southwestern Europe". Quaternary Science Reviews, 21: 2047-2066.

Carrión, J.S.; Yll, E.I.; Willis, K.J. y Sánchez, P. 2004: "Holocene forest history if the western plateaux the Segura mountains (Murcia, Southeastern, Spain)". Review of Paleobotany and Palinology 132, 3-4: 219-236.

Chabal, L. 1988: "Pourquoi et comment prélever les charbons de bois pour la période antique. Les méthodes utilisées sur le site de Lattes (Hérault)". Lattara 1: 188-222.

Ferreras Chasco, C. 1987: "Sobre la amplitud y significación bioclimática de los encinares". Anales de Geografía Universidad Complutense, 7: 103-111.
Forteza, J.; Rubio, J.C. y Gimeno, E. 1995: El catálogo de suelos de la Comunitat Valenciana. Consellería de Agricultura, Pesca y Alimentación. Valencia.

Gale, R. 1999: "Gatas: análisis antracológico”. En P. Castro, R. Chapman, S. Gili, V. Lull, R. Micó, C. Rihuete, R. Risch y M.E. Sanahuja (eds.): Proyecto Gatas 2. La dinámica arqueoecológica de la ocupación prehistórica. Monografías Arqueología 4. Junta de Andalucía. Consejería de Cultura. Sevilla: 296-310.

Giralt, S.; Burjachs, F.; Roca, J.R. y Julià, R. 1999: "Late glacial to early Holocene environmental adjustament in the Mediterranean semi-arid zone of the Salines playa-Lake (Alicante, Spain)". Journal of Paleolimnology 21: 449-460.

Grau Almero, E. 1998: “Antracoanálisis de los restos de madera carbonizada del yacimiento". En M.J. de Pedro Michó (ed.): La Lloma de Betxí, (Paterna, Valencia). Un poblado de la Edad del Bronce. Trabajos varios del Servicio de Investigación Prehistórica 94. Valencia.

Guilabert, A.P.; Jover F.J. y Fernández, J. 1999: "Las primeras comunidades agropecuarias del Río Vinalopó (Alicante)". II Congrés del Neolitic a la Península Ibèrica. Saguntum-PLAV, Extra-2: 283-290.

Gutiérrez Oliva, A. y Plaza Pulgar, F. 1967: Características físico-mecánicas de las maderas españolas. Ministerio de Agricultura. Dirección General de Montes, Caza y Pesca Fluvial. I.F.I.E. Madrid.

Heinz, C.; Figueiral, I.; Terral, J.-F. y Claustre, F. 2004: "Holocene vegetation changes in the northwestern Mediterranean: new palaeoecological data from charcoal analysis and quantitative eco-anatomy". The Holocene 14, 4: 621-627.

Hernández, M.S.; Fumanal, M.P.; Martínez, J.; Batle-Sales, J.; Bordàs, V.; Ferrer, C. y Serna, A. 1996: "Un modelo de estudio interdisciplinar: El Cabezo Redondo (Villena, Alicante) y su entorno". XXIII Congreso Nacional de Arqueología (Elche 1995): 143-160. Elche.

Jover Maestre, F.J. 1999: Una nueva lectura del “Bronce Valenciano”. Universidad de Alicante. Alicante.

Jover Maestre, F.J. 2006: "La ocupación prehistórica en el valle de Elda". En A.M. Poveda Navarro y J.R. Valero Escandell (coord.): Historia de Elda I. Ayuntamiento de Elda. Universidad de Alicante. Elda: 29-43.

Jover Maestre, F.J. y López Padilla, J.A. 1999: “Campesinado e Historia. Consideraciones sobre las comunidades agropecuarias de la Edad del Bronce en el Corredor del Vinalopó". Archivo de Prehistoria Levantina XXIII: 233-257. 
Jover Maestre, F.J. y López Padilla, J.A. 2004: "2100-1200 AC. Aportaciones al proceso histórico en la cuenca del río Vinalopó". En L. Hernández y M.S. Hernández (eds.): La Edad del Bronce en Tierras Valencianas y Zonas limitrofes. Ayuntamiento de Villena. Instituto alicantino de Cultura Juan Gil-Albert. Villena: 285-302.

Jover Maestre, F.J. y López Padilla, J.A. 2005: $B a$ rranco Tuerto y el proceso histórico en el corredor del Vinalopó durante el II milenio AC. Fundación José María Soler. Villena.

Jover Maestre, F.J.; López Padilla, J.A.; Machado Yanes, M. del C.; Hérraez Martín, M.I.; Rivera Núñez, D.; Precioso Arévalo, M.L. y Llorach Asunción, R. 2001: "La producción textil durante la Edad del Bronce: un conjunto de husos o bobinas de hilo del yacimiento de Terlinques (Villena, Alicante)". Trabajos de Prehistoria 58 (1): 171-186.

Machado, M.C.; Jover, F.J. y López, J.A. 2004: “Primeras aportaciones antracológicas del yacimiento de Terlinques (Villena, Alicante)”. En M. Hernández y L. Hernández (eds.): La Edad del Bronce en tierras valencianas y zonas limitrofes. Ayuntamiento de Villena. Instituto alicantino de Cultura Juan Gil-Albert. Villena: 241-246.

Matarredona Coll, E. 1983: El Alto Vinalopó. Estudio geográfico. Instituto de Estudios Alicantinos. Alicante.

Palamarczuk, V. 2004: “Cocción experimental de cerámica con estiércol de llama". Intersecciones en Antropología on line 18350-373x.

Palomar Macián, V. 1996: "Sobre la utilización de las cuevas en el Bronce valenciano y su relación con los yacimientos al aire libre". Quaderns de. Prehistòria i Arqueologia Castellonense 17: 157174.

Pedro Michó, M.J. de 1990: "La Lloma de Betxí (Paterna): datos sobre técnicas de construcción en la Edad del Bronce". Archivo de Prehistoría Levantina XX: 327-350.

Pedro Michó, M.J. de 1998: La Lloma de Betxí (Paterna, Valencia). Un poblado de la Edad del Bronce. Trabajos Varios del Servicio de Investigación Prehistórica 94. Valencia.

Piqué i Huerta, R. 1999: Producción y uso del combustible vegetal: una evaluación arqueológica. Treballs d'etnoarqueologia 3. CSIC. Madrid.

Piqué i Huerta, R. 2006: "los carbones y las maderas de contextos arqueológicos y el paleoambiente". Ecosistemas 15 (1): 31-38.

Precioso Arévalo, M.L. y Rivera Núñez, D. 1999: "Estudio paleoetnobotánico". En F.J. Jover Maestre y J.A. López Padilla (eds.): II Campaña de excavaciones arqueológicas en Terlinques (Villena, Alicante). Memoría científica anual. Memorias ar- queológicas y paleontológicas de la Comunidad Valenciana. Valencia.

Ramón Burillo, J. y Ramírez Piqueras, J. 2004: La tecnología alfarera en la Edad del Bronce: Cabezo Redondo" (Villena), modelo de estudio. En M. Hernández y L. Hernández (eds.): La Edad del Bronce en Tierras Valencianas y Zonas limitrofes. Ayuntamiento de Villena. Instituto alicantino de Cultura Juan Gil-Albert. Villena: 369-377.

Rivas Martínez, S. 1987: Memoria del mapa de series de vegetación de España. ICONA. Madrid.

Rodríguez Ariza, M.O. 1992: "Human-plant relationships during the copper and Bronze Age in the Baza and Guadix basins (Granada, Spain)". Bulletin de la Société Botanique de la France 139. Activités botaniques (2/3/4): 451-464.

Rodríguez Ariza, M. ${ }^{\text {a }}$ O. 2000: “Análisis antracológico de Peñalosa". En F. Contreras (coord.): Proyecto Peñalosa. Análisis histórico de las comunidades de la Edad del Bronce del Piedemonte meridional de Sierra Morena y Depresión de Linares-Bailén Arqueología monografías, 10. Junta de Andalucía. Consejería de Cultura. Sevilla: 257-272.

Rodríguez Ariza, M.O.; Nájera, T. y Ros, M. ${ }^{a}$ T. 1999: "Una valoración paleoecológica de la Motilla de Azuer a partir del análisis antracológico". En J. Capel (ed.): Arqueometría y arqueología Universidad de Granada. Granada: 11-23.

Rodríguez Ariza, M.O. y Ruiz Sánchez, V. 1995: "Antracología y palinología del yacimiento argárico de Castellón Alto (Galera, Granada)". Anuario Arqueológico de Andalucía 1992, II: 169-176.

Rodríguez Ariza, M.O.; Ruiz, V.; Buxó, R. y Ros, M. 1996: "Paleobotany of a Bronze Age community, Castellón Alto (Galera, Granada, Spain)". Actes du Colloque de Périgueux, 1995. Supplément à la Revue d'Archeométrie: 191-196.

Schiffer, M.B. 1976: Behavioral archaeology. Academic Press. New York.

Schiffer, M.B. 1977: Formation processes of the archaeological record. University of Nuevo Mexico. Alburquerque.

Schweingruber, F.H. 1990: Anatomy of European woods. Verlag Paul Haupt. Stuttgart.

Soler García, J.M. 1956: El yacimiento musteriense de la Cueva del Cochino (Villena, Alicante). Trabajos Varios del Servicio de Investigación Prehistórica, 19. Valencia.

Soler García, J.M. 1987: Excavaciones arqueológicas en Cabezo Redondo (Villena, Alicante). Instituto de Cultura Juan Gil-Albert. Alicante.

Soler García, J.M. y Fernández Moscoso, E. 1970: "Terlinques. Poblado de la Edad del Bronce en Villena (Alicante)". Papeles del Laboratorio de Arqueología de Valencia 10: 27-65. 
Toledo, V. 1993: "La racionalidad ecológica de la producción campesina". En E. Sevilla y M. González (eds.): Ecología, campesinado e Historia. Genealogía del poder 22. Ed. La Piqueta. Madrid: 197-218.

Uzquiano, P. 1990: “Analyse anthracologique du Tossal de la Roca (Paléolithique Supérieur Final- Epipaléolithique, province d'Alicante, Espagne)". 1st. European Conference on wood and archaelogy, PACT 22: 209-217.
Verdasco Cebrián, C.C. 2001: "Depósitos naturales de cueva alterados: estudio microsedimentológico de acumulaciones producidas en el neolítico valenciano por la estabulación de ovicápridos". Cuaternario y Geomorfología 15 (3-4): 85-94.

Y1l, R.; Carrión, J.S.; Pantaleón, J.; Dupré, M.; De La Roca, N.; Roure, J.M. y Pérez Obiol, R. 2003: "Palinología del Cuaternario reciente en la Laguna de Villena (Alicante, España)". Anales de Biología 25: 65-72. 